\title{
UNA APROXIMACIÓN AL CRIMEN INTERNACIONAL DE AGRESIÓN
}

\author{
José Manuel Díaz Soto*
}

\begin{abstract}
Resumen: El presente artículo expone el desarrollo del crimen de agresión en el ámbito del derecho internacional, partiendo desde sus antecedentes hasta llegar a la definición alcanzada en la ciudad de Kampala, Uganda, durante la primera Conferencia de Revisión del Estatuto de la Corte Penal Internacional, el 11 de junio de 2010. Seguidamente, de una manera detallada analiza el régimen jurídico que rodea al crimen de agresión, su naturaleza jurídica, su concordancia con los principios de legalidad y complementariedad, el tipo objetivo descrito, el umbral de gravedad y antijuridicidad del acto de agresión como fundamento de la responsabilidad penal individual, el elemento subjetivo o mens rea del crimen, la figura de la tentativa, también los mecanismos de activación de la jurisdicción de la CPI.

Complementariamente, este trabajo analiza las implicaciones que tiene el consenso alcanzado en Kampala a través de la Resolución RC/Res. 6, instrumento que representa un avance significativo para el crimen de agresión en el derecho internacional aunque ha sido objeto de diversas críticas. Partiendo
\end{abstract}

* Abogado de la Universidad Externado de Colombia. Magíster en Ciencias Penales y Criminológicas de la misma Universidad. Candidato a doctor en Derecho de la Universidad Pompeu Fabra (Barcelona). Docente de Derecho Penal de la Universidad Externado de Colombia (Bogotá, Colombia). El autor se desempeña en la actualidad como Defensor Delegado para la Política Criminal y Penitenciaria en la Defensoría del Pueblo.E-mail: diazsoto@hotmail.com; josem.diaz@uexternado.edu.co Bogotá, Colombia. Fecha de recepción: 13 de septiembre de 2014. Fecha de modificación: 28 de noviembre de 2014. Fecha de aceptación: 16 de diciembre de 2014. Para citar el artículo: José Manuel DíAZ Sото. "Una aproximación al crimen internacional de agresión", Revista Derecho Penal y Criminología, vol. 35, n. 99, julio-diciembre de 2014, Bogotá, Universidad Externado de Colombia, 2014, pp. 11-60. DOI: http://dx.doi.org/10.18601/01210483.v35n99.02 
de este escenario, el autor toma posición con la finalidad de encontrar una aplicación correcta de la norma en el ordenamiento jurídico colombiano.

Palabras clave: Guerra de agresión, Estatuto de la Corte Penal Internacional, crimen de agresión, gravedad del acto de agresión, Conferencia de Revisión del Estatuto de la Corte Penal Internacional, Resolución RC/Res. 6.

\title{
AN APROACH TO THE CRIMEN OF AGRESSION
}

\begin{abstract}
This article shows the historical development of the crime of aggression in international law, from its precedents to the amendments at the ICC Statute, introduced during the First Review Conference of the International Criminal Court on June 11, 2010. Furthermore, the article explores the legal status of the crime of aggression, its legal nature, the conduct itself or actus reus, the mental element or mens rea, the relation between the crime of aggression and the principles of legality and complementarity, the character, scope and gravity of the act of aggression as a basis of individual criminal liability, the attempt to commit the crime of aggression and the complex procedure to activate the ICC's jurisdiction.

Complementary, this work analyses the implications of the consensus reached in Kampala through the Resolution RC/Res. 6, witch represents a significant advance for the crime of aggression in international law but has been object of several criticism. From this scenario, the author assumes a position that allows the correct application of the norm in the Colombian legal system.

Keywords: War of aggression, The Rome Statute of the International Criminal Court, crime of aggression, gravity of the act of aggression, Review Conference of the International Criminal Court, Resolution RC/Res. 6.
\end{abstract}

\section{EL CRIMEN DE AGRESIÓN COMO CRIMEN DE DERECHO INTERNACIONAL}

Lo primero que habría que señalar en relación con el crimen de agresión, aun cuando pueda ser considerado una obviedad, es que se trata de un crimen de derecho internacional, esto es, una conducta que lleva asociadas las consecuencias propias del derecho penal, en particular, la imposición de una pena, pero cuyo carácter punible se deriva directamente de normas internacionales, bien sean estas de orden convencional o consuetudinario. En otras palabras, el crimen de agresión hace parte del derecho internacional penal ${ }^{1}$, entendiendo por tal, siguiendo la definición de ОTTO

1 Si bien algún sector de la doctrina prefiere el concepto de derecho penal internacional al de derecho internacional penal, limitando el segundo al derecho transnacional penal, considero que el cuerpo normativo estudiado resulta mejor reflejado en su esencia por este último término, en particular, la expresión hace énfasis en el origen internacional de estas disposiciones de carácter penal. 
TRIFFTERER, "la totalidad de normas de Derecho Internacional de naturaleza penal que conectan consecuencias jurídicas típicas de Derecho Penal a una conducta decisiva -a saber, el crimen internacional- y como tal pueden ser aplicadas directamente"2.

La aplicación directa de las normas de derecho internacional que consagran los crímenes internacionales, es decir, la represión penal de dichas conductas sin necesidad de que hayan sido incorporadas en los ordenamientos nacionales, obedece a la naturaleza igualmente internacional de los bienes jurídicos que pretenden tutelar; los cuales conciernen a la comunidad internacional en su conjunto ${ }^{3}$. En efecto, el rasgo característico común del genocidio, los crímenes contra la humanidad, los crímenes de guerra ${ }^{4}$ y el crimen de agresión es que atentan contra la paz, la seguridad y el bienestar de la comunidad internacional; de ahí que el artículo 5. del Estatuto de la Corte Penal Internacional (en adelante ECPI) atribuya a la Corte competencia para su enjuiciamiento al identificarlos como "los crímenes más graves de trascendencia para la comunidad internacional en su conjunto".

Es por esta razón que frente a los crímenes de derecho internacional no son oponibles, con miras a evitar su enjuiciamiento, las normas de los ordenamientos jurídicos de los Estados en cuyo territorio tuvieron lugar o del que son nacionales sus autores; en especial, se trata de delitos respecto de los cuales no puede argüirse ningún tipo de inmunidad, son imprescriptibles y la posibilidad de conceder amnistías o indultos a sus autores se encuentra estrictamente condicionada ${ }^{5}$.

Adicionalmente los crímenes internacionales, en vista de la naturaleza internacional de los bienes jurídicos que lesionan, llevan aparejada la obligación para los Estados de perseguirlos y castigarlos; deber que en principio recae en cabeza del Estado en cuyo territorio tuvieron ocurrencia, pero que, en su defecto, puede ser desarrollado

2 Citado por Kai Ambos. “¿Castigo sin soberano? La cuestión del ius puniendi en Derecho Penal Internacional, Una primera contribución para una teoría del derecho penal internacional consistente". Persona y Derecho, vol. 68, n. ${ }^{\circ}$ 1, 2013, pp. 5 a 38 y 10.

3 Entre otros muchos Ambos. “Castigo sin soberano?”, cit. Gerhard Werle. Tratado de Derecho Penal Internacional. C. CÁrdenas Aravena, J. Couso Salas, M. Gutiérrez Rodríguez (Trads.). Valencia, Tirant lo Blanch, 2011. M. CHERIF BAssiounI. Crimes Against Humanity: Historical Evolution and Contemporary Application. Cambridge, Cambridge University Press, 2011. ANTONIO CASSESE. Cassese's International Criminal Law, 3. ${ }^{a}$ ed. Oxford, Oxford University Press, 2013, p. 103. DAVID J. LuBAN. "Fairness to rightness: Jurisdiction, legality, and the legitimacy of International Criminal Law". Georgetown University Law Center, julio de 2008.

4 A condición de haber sido cometidos de forma generalizada o sistemática: cfr. ord. 1. ${ }^{\circ}$ art. 8 Estatuto de Roma de la Corte Penal Internacional.

5 En relación con las condiciones bajo las cuales resultaría admisible una amnistía por crímenes internacionales a la luz del derecho internacional, cfr. KAI AmBOs. "El marco jurídico de la justicia de transición”. En: AA.vv. Justicia de transición. Con informes de América Latina, Alemania, Italia y España. Kai Ambos y Ezequiel Malarino (EDS.). Bogotá, Temis, 2010. 
por cualquier Estado en ejercicio del principio de jurisdicción universal o por la CPI bajo los lineamientos del principio de complementariedad ${ }^{6}$.

En lo que respecta propiamente al crimen de agresión como crimen de derecho internacional, cabe destacar que desde la sentencia del Tribunal Militar Internacional de Nuremberg (en adelante TMI) se reconoció que la guerra no solo afecta a los Estados beligerantes, sino a toda la comunidad internacional, es más, el crimen de agresión, en ese momento bajo la denominación de crimen contra la paz, fue considerado por el TMI como el crimen internacional supremo; solo distinguible de otros crímenes internacionales, y en particular de los crímenes de guerra, por su dimensión ${ }^{7}$. Además, la prohibición de agresión hoy en día es ampliamente considerada como norma de ius cogens, es decir, aquella que no puede ser violada ni por un tratado ni por el desarrollo de una nueva costumbre internacional ${ }^{8}$.

De lo expuesto bien puede afirmarse que el estudio del crimen de agresión no constituye una mera inquietud académica carente de trascendencia en el plano nacional, por el contrario, dada su condición de crimen fundamental del derecho internacional - core crimen- la conducta de nuestros dirigentes y de quienes presiden los Estados que nos circundan será valorada conforme a la definición del crimen de agresión; lo que demanda un profundo análisis de esta conducta delictiva y de las condiciones para su persecución ${ }^{9}$.

6 Para una detallada explicación de la jurisdicción universal, la obligación de perseguir y la justicia transicional, ver WERLE, ob. cit., pp. 133 y ss.

7 Jennifer Trahan. “The Rome Statute's Amendment on the Crime of Aggression: Negotiations at the Kampala Review Conference”. International Criminal Law Review, vol. 11, 2011, nota al pie 7. También cfr. Erin Creegan. "Justified Uses of Force and the Crime of Aggression". Journal of International Criminal Justice, vol. 10, Oxford University Press, 2012, pp. 62-63. "There is an inherent awkwardness in placing the crime of aggression next to the other crimes of the Rome Statute, the most severe awkwardness is caused by our awareness of the fundamentally evil nature of all human rights crimes and that these crimes require serious, pervasive human suffering before the International Criminal Court's jurisdiction is triggered"; y continúa: "while genocide, crimes against humanity or war crimes are inexcusable abuses, aggression, by contrast is a more political crime [...]. The harm of aggression is the insult to a state's territorial independence and sovereignty, itself a political idea". Dice asimismo el autor: "aggression can be accomplished without a single person being physically harm. Aggression can also be peace-oriented state policy that may not only yield no discrete harm, and can even prevent human suffering". El mencionado autor trae a colación el "principio del daño" (the harm principle) formulado por John Stuart Mill para concluir: "without adversely affected human victims, it is hard to put a crime like aggression in a category similar to war crimes or crimes against humanity or genocide. And it does not seem to belong next to them: it almost demeans them. While aggression can lead to these most incredible for of harms, it may be better to punish those acts instead".

8 Mary Ellen O'Connell y Mirakmal Niyazmatov. "What is Agression? Comparing the Jus ad Bellum and the ICC Statute”. Journal of International Criminal Justice”, vol. 10, Oxford University Press, 2012, p. 190.

9 Tarea que, debe reconocerse, la doctrina nacional ya ha iniciado; ver ILICH FELIPE CORREDOR CARVAJAL. 
A continuación intentaremos adelantar un estudio omnicomprensivo del crimen de agresión, partiendo de sus antecedentes hasta llegar a la definición consagrada en el ECPI tras su primera conferencia de revisión; de igual modo, analizaremos los interrogantes que suscita la inserción del crimen de agresión frente a las instituciones de la parte general del Estatuto de la CPI y su régimen de jurisdicción. Tras este desarrollo, esperamos brindar al lector un panorama general, aunque completo, del crimen de agresión que facilite estudios posteriores y más detallados en esta materia.

\section{LOS ANTECEDENTES DEL CRIMEN DE AGRESIÓN}

La definición del crimen de agresión alcanzada durante la primera conferencia de revisión del Estatuto de la CPI, llevada a cabo en la ciudad de Kampala, Uganda, del 31 de mayo al 11 de junio de 2010, es el más reciente logro de un proceso que inició a principios del siglo $\mathrm{xx}$, consistente en la paulatina renuncia al uso de la fuerza armada como recurso al que válidamente podían acudir los Estados en el manejo de sus relaciones internacionales.

Al respecto, téngase presente que el crimen de agresión no solo supone la renuncia a la concepción decimonónica del ius ad bellum como atributo propio de la soberanía de los Estados. Adicionalmente, la responsabilidad penal individual por el crimen de agresión requirió de un escenario internacional en el que imperara la prohibición jurídica al uso de la fuerza armada entre los Estados, es decir, en el que el empleo de la fuerza no fuera un derecho sino una excepción; lo que solo se alcanzó con la adopción de la Carta de las Naciones Unidas (en adelante CNU) en el año 1948 y, más exactamente, con la definición de acto de agresión consagrada en la Resolución 3314 de la Asamblea General de las Naciones Unidas (en adelante AGNU) del año 1974.

A continuación expondremos los principales hitos del proceso al que se viene haciendo referencia, lo cual consideramos necesario para una adecuada comprensión de la definición de crimen de agresión reciente incorporada al Estatuto de la CPI.

La doctrina consultada coincide en afirmar que no fue sino con la firma del Pacto de la Sociedad de las Naciones (1919) ${ }^{10}$ que se limitó, mas no prohibió, el uso de la fuerza armada, y en particular de la guerra, como instrumento de política internacional. En especial, se estableció un régimen de responsabilidad estatal, que no individual, por acudir al uso de la fuerza sin agotar los procedimientos previstos en dicho

El crimen de agresión en Derecho Penal Internacional. Responsabilidad del individuo por acto de Estado. Bogotá, Universidad del Rosario, 2012.

10 Aunque se había hecho un llamado a la solución pacífica de los conflictos entre Estados antes de iniciar una guerra, con los tratados que pusieron fin a la Guerra de los 30 años en Europa, más conocidos como la Paz de Westfalia, en 1648. O’Connell y Niyazmatov, ob. cit., p. 189. 
instrumento ${ }^{11}$. A no dudarlo, fue el inusitado sufrimiento producido por la Primera Guerra Mundial lo que condujo a esta primera limitación jurídica del ius ad bellum ${ }^{12}$.

Por la misma vía, el Proyecto de Tratado de Asistencia Mutua de 1923, elaborado en el seno la Sociedad de las Naciones, calificaba los actos de agresión como "crimen internacional". Sin embargo, el proyecto no hacía ninguna referencia a la posibilidad de declarar la responsabilidad penal individual de sus autores, por lo que resulta lógico concluir que la mención a un "crimen internacional" constituía un mero recurso semántico para reafirmar la ilicitud de los actos de agresión en el escenario internacional, mas no la introducción de una conducta punible con base en normas de derecho internacional ${ }^{13}$.

De forma más categórica, el Protocolo para la Solución Pacífica de Controversias Internacionales (Protocolo de Ginebra de 1924) definió la guerra de agresión como un "crimen internacional que merece el rechazo de todos los miembros de la comunidad internacional" 14 . Así mismo, el artículo 10 del Protocolo caracterizaba a los Estados infractores de sus disposiciones como auténticos "Estados agresores"15. Sin embargo, el Protocolo tampoco estableció un régimen de responsabilidad penal individual por la comisión del crimen de agresión, y además, a falta del número necesario de ratificaciones, jamás entró en vigor.

Pese a la trascendencia de los antecedentes hasta ahora señalados, el paso decisivo hacia la completa prohibición de hacer la guerra estuvo representado en el Tratado General de Renuncia a la Guerra, mejor conocido como Pacto Briand-Kellog, del 27 de agosto de $1928^{[16]}$. En su preámbulo, las altas partes contratantes declaran "haber llegado el momento de proceder a una franca renuncia a la guerra como instrumento de la política nacional". La relevancia del Tratado puede advertirse del hecho de haber sido invocado por el Tribunal Militar Internacional (TMI) como prueba del carácter consuetudinario de los crímenes contra la paz.

11 Werle, ob cit., p. 737 y ss. CASILDA RUEDA FeRnández. Delitos de Derecho Internacional, tipificación y represión internacional. Barcelona, Bosch, 2002, p. 129. LyaL S. Sunga. "La jurisdicción "ratione materiae" de la Corte Penal Internacional (arts. 5. ${ }^{\circ}$ a $10 .^{\circ}$ del Estatuto de Roma)". En: AA.vv. El Estatuto de Roma de la Corte Penal Internacional. Kai Ambos y OsCAR Julian Guerrero (comps.). Bogotá, Universidad Externado de Colombia, p. 240.

12 No obstante, cabe destacar que Wherle identifica un cuestionamiento al ius ad bellum, que no una prohibición, en las Convenciones para la Resolución Pacífica de Conflictos Internacionales (La Haya 1899 y 1907).

13 RUEDA FERNÁNDEZ, ob. cit., p. 130.

14 Ibíd.

15 WERLE, ob cit., p. 739.

16 WeRLE, ob cit., p.740 y RUEDA FERNÁNDEZ, ob. cit., p. 130. 
De lo hasta ahora expuesto resulta válido concluir que al inicio de la Segunda Guerra Mundial el uso de la fuerza armada entre Estados, por fuera de los supuestos de legítima defensa y uso mancomunado de la fuerza para garantizar la paz y la seguridad internacional, se hallaba proscrito por el derecho internacional. Sin embargo, y pese a lo señalado por el TMI, no existía disposición alguna que previera responsabilidad penal individual por la comisión de actos de agresión, mucho menos para los dirigentes del Estado agresor ${ }^{17}$.

El primer instrumento internacional en el que se estableció que el desarrollo de una guerra de agresión constituye un auténtico crimen que compromete la responsabilidad penal de quienes intervinieron en su planeación y ejecución fue el Estatuto del TMI ${ }^{18}$ que en su artículo 6 (a), bajo la denominación de 'crímenes contra la paz', consagró como conducta delictiva el "planeamiento, preparación, iniciación o ejecución de una guerra de agresión o de una guerra en violación de tratados internacionales, acuerdos y seguridades, o la participación en un plan común o en una conspiración para ejecutar cualquiera de los actos precedentes" ${ }^{19}$.

En relación con la definición de crimen contra la paz recogida en el Estatuto del TMI, cabe destacar que lo que es objeto de punición es el desarrollo de una guerra de agresión; de modo que cualquier otro acto de agresión estaría por fuera del ámbito de los crímenes contra la paz. La anterior aclaración resulta pertinente, pues el texto del Estatuto parecería sugerir que se sanciona tanto la conducción de una guerra de agresión como de una guerra en contravención de los tratados internacionales. No obstante, la doctrina consultada coincide en sostener que el correcto entendimiento de la norma es que penaliza una guerra de agresión como guerra contraria al derecho internacional ${ }^{20}$; así lo reafirma la definición de crimen contra la paz contenida en la ley n. ${ }^{\circ} 10$ del Consejo de Control Aliado, en la que se habla de "guerra de agresión en violación del Derecho internacional y los tratados".

De igual modo, debe señalarse que a pesar de que el artículo 6 (a) no establece ningún condicionamiento para los autores o partícipes del crimen contra la paz -por el contrario, adopta una redacción extensiva que parecería comprometer la responsabilidad penal de todo aquel que hubiera participado en cualquier forma en la planeación o ejecución de una guerra de agresión-, el TMI conceptuó que solo podían ser considerados responsables por crímenes contra la paz aquellas personas que tenían

17 WERLE, ob cit., p. 746.

18 Para una detallada exposición de los antecedentes del Estatuto del TMI y del desarrollo del juicio ante el tMi ver James OWEn. Nuremberg, el mayor juicio de la historia. EnCARnA Belmonte y FERRAN Esteve (trads.). Barcelona, Crítica, 2007.

19 Carta del Tribunal Militar Internacional de Nuremberg (1945). La versión en español puede ser consultada en www.ehu.es/ceinik/tratados/7TRATADOS RELATIVOSACRIMENESDEGUERRA/CG73.pdf Consultado el 8 de diciembre de 2014.

20 WERLE, ob cit., p. 751. 
a su cargo la conducción política o militar del Estado agresor ${ }^{21}$. En otras palabras, por vía jurisprudencial se reconoció el carácter del crimen de agresión como crimen de dirigentes; rasgo que se mantiene en la definición recientemente incorporada al Estatuto de la CPI.

\section{LA CONSAGRACIÓN DEL CRIMEN DE AGRESIÓN Y EL PRINCIPIO DE LEGALIDAD}

Ahora bien, una cuestión que no puede pasarse por alto en relación con la consagración del crimen contra la paz en el Estatuto del TMI es la de si tal hecho resultó o no contrario al principio de legalidad, en particular, si desconoció la prohibición de aplicación retroactiva de la ley penal. Sobre este punto, lo primero que habría que aclarar es que el principio de legalidad en materia de derecho internacional penal carece del mismo contenido y alcance que usualmente se le reconoce a esta norma rectora en las legislaciones nacionales ${ }^{22}$. Así, por ejemplo, en el derecho internacional penal la costumbre internacional es reconocida como fuente de los crímenes internacionales, de modo que el aforismo nullum crimen sine lege es remplazado por nullum crimen sine iure, esto es, no existe crimen internacional sin norma de derecho internacional que lo consagre, bien sea esta de carácter convencional o consuetudinario. Adicionalmente, el principio de legalidad no es concebido como una garantía para el procesado sino como un principio de justicia, de modo que de lo que se trata es de determinar si el castigo resulta justo, más que si el acusado se hallaba en capacidad de conocer todos los elementos de la conducta punible que se le imputa ${ }^{23}$. Así, por ejemplo, LuBAN sostiene que siendo los crímenes internacionales conductas especialmente reprochables bajo el consenso de la comunidad internacional -malum in se-, los procesados en Nuremberg no podían argüir una expectativa razonable de estar actuando conforme a derecho ${ }^{24}$, aun cuando los contornos del crimen de agresión no estuvieran precisados al inicio de la Segunda Guerra Mundial. Así entendido el principio de legalidad, debe dársele la razón a WHERLE cuando sostiene que la imputación por crímenes contra la paz durante el juicio de Nuremberg no supuso un quebrantamiento del señalado principio, pues "la penalización individual de la guerra de agresión estaba con ello ${ }^{25}$

21 Así se desprende de los apartes de la sentencia del TMI, del 1. ${ }^{\circ}$ de octubre de 1946, en los que se funda la absolución de los acusados Von Schirach y Schacht por el cargo de crímenes contra la paz. Parte 22 y ss.

22 En relación con el contenido y alcance del principio de legalidad en el ámbito del derecho penal internacional ver HANS-HeINRICH JeSCHECK. "The General Principles of International Criminal Law Set Out in Nuremberg, as Mirrored in the ICC Statute". Journal of International Criminal Justice, vol. 2(1), Oxford University Press, 2004, y LuBAN, ob. cit.

23 JESCHECK, ob. cit., p. 42.

24 LubAN, ob. cit., p. 20.

25 Refiriéndose a los antecedentes arriba enunciados, así como a las disposiciones del Tratado de Paz de Versalles en las que se responsabilizaba al Kaiser alemán por el desencadenamiento de la primera guerra mundial (nota fuera de la cita). 
al alcance como consecuencia lógica de la proscripción de la guerra, aun antes de la Segunda Guerra Mundial"26. No obstante, si se parte de una concepción más amplia del principio de legalidad cabría también reconocer como acertada la posición de PERDOMO, para quien tal principio supone "que la norma haya sido establecida en la comunicación entre personas con anterioridad al hecho" 27 ; condición que difícilmente existía al momento en que se instauró el TMI de Nuremberg, cuando menos en lo que respecta al crimen de agresión. En igual sentido debe destacarse la posición de MiLANOVIC $^{28}$, quien considera que el principio nullum crimen sine lege, especialmente después de la adopción del ECPI, debe ser entendido exactamente como tal, es decir, no hay crimen sin una norma positiva que lo consagre, que para este caso vendría representada por un tratado.

Ahora bien, independientemente de esta discusión, lo cierto es que con el Estatuto del TMI se reconoció por primera vez que el inicio de una guerra por fuera de los lineamientos del derecho internacional supone una auténtica conducta punible que compromete la responsabilidad penal de los líderes del Estado agresor.

\section{DESARROLLOS CONTEMPORÁNEOS DEL CONCEPTO DE AGRESIÓN}

Posteriormente, la Comisión de Derecho Internacional (en adelante CDI), al formular los Principios de Nuremberg ${ }^{29}$ en desarrollo del mandato otorgado por la AGNU, reafirmó que la preparación, planeación e inicio de una guerra de agresión constituye un crimen de derecho internacional -Principio IV-cuya punición no está supeditada a las disposiciones de derecho interno -Principio II- y frente al cual no puede oponerse ningún tipo de inmunidad -Principio III-.

Paralelamente la CNU, tal como arriba se esbozó, consagró en su artículo 2 (4) la prohibición de la amenaza o uso de la fuerza contra la integridad territorial o la independencia política de cualquier Estado de modo incompatible con los propósitos de

26 WeRLE, ob. cit., p. 747.

27 Cabe aclarar que PERDOMo cuestiona la vigencia, todavía en la actualidad, del derecho internacional penal. En particular, considera que con esta denominación se hace referencia a medidas coercitivas tendientes a la consolidación de un orden jurídico aún no vigente; medidas que, en todo caso, resultan justificadas por el propósito de consecución del ideal de paz perpetua. JorGE FERnANDo PERDOMO TORRES. Justicia penal internacional. Reflexiones acerca del delito político, extradición y amnistía. Lima, Grijley, 2006, p. 58.

28 Marko Milanovic. "Aggression and legality". Journal of International Criminal Justice, vol. 10, Oxford University Press, 2012, p. 169. El mencionado autor encuentra una ambigüedad en la aplicación del principio "nullum crimen sine lege" en el TMI de Nuremberg, ya que no se sabe si se trata de una prohibición de retroactividad de la ley o si es, más bien, un "principio de justicia" que puede ser moldeado de ser necesario.

29 Informe de la Comisión de Derecho Internacional sobre la labor realizada en su 5. período de sesiones, 5 de junio a 29 de julio de 1950. En Werle, ob. cit., p. 891. 
las Naciones Unidas. La disposición anotada suscita un interrogante que no ha sido abordado por la doctrina consultada, a saber: ¿la CNU amplió el alcance del crimen de agresión, incluyendo como conducta punible internacional aquellos usos de la fuerza incompatibles con los propósitos de las NU, pero que no alcanzan el grado de guerra de agresión? En otras palabras, se trata de determinar si la proscripción del uso de la fuerza armada contra la integridad territorial o la independencia política de cualquier Estado, consagrada en el artículo 2 (4) de la CNU, ensanchó el catálogo de conductas punibles bajo el derecho internacional; de modo que no solo sería objeto de sanción penal la planeación, preparación y ejecución de una guerra de agresión, como se estipuló en el Estatuto del TMI, sino cualquier uso de la fuerza armada incompatible con la CNU.

Al respecto, pese a que el texto de la CNU y la definición de agresión alcanzada en 1974 parecerían extender el crimen de agresión a supuestos distintos al de la guerra de la agresión, no puede perderse de vista que en distintos instrumentos internacionales tras Nuremberg se reafirmó que los crímenes contra la paz solo se configuran en presencia de una guerra de agresión, no así frente a usos ilícitos de la fuerza armada de menor entidad. Así, por ejemplo, la propia Resolución 3314 de la AGNU, pese a disponer una definición amplia del concepto de agresión, únicamente consagra como crimen contra la paz el desarrollo de una guerra de agresión; aun cuando reconoce que la agresión, en todas sus formas, da lugar a responsabilidad internacional para el Estado agresor - art. 5. - - De igual modo, la formulación de los Principios de $\mathrm{Nu}$ remberg, a la que arriba se hizo mención, solo reconoce como crimen internacional la planeación, preparación o ejecución de una guerra de agresión; no así otras formas ilícitas de uso de la fuerza armada en el escenario internacional, es decir, otros actos de agresión. En el mismo sentido, el texto definitivo del Proyecto de Código de Crímenes contra la Paz y la Seguridad de la Humanidad ${ }^{30}$, aprobado por la CDI en 1996, define el crimen de agresión como la intervención de un dirigente en la "planificación, preparación, desencadenamiento o libramiento de una guerra de agresión cometida por un Estado"; lo que reafirma que solo la guerra de agresión daba lugar a responsabilidad penal internacional ${ }^{31}$.

En conclusión, con anterioridad a la definición de crimen de agresión lograda en Kampala, el derecho internacional limitaba la responsabilidad penal por el crimen de agresión a la planeación, preparación o ejecución de una guerra de agresión; de

30 Informe de la Comisión de Derecho Internacional sobre la labor realizada en su $48^{\circ}$ período de sesiones, 6 de mayo a 26 de julio de 1996. Doc. A/51/10. Anexo de la obra de CASILDA RuEDA FERnÁndeZ, oB. CIT.

31 No obstante, debe reconocerse que el anteproyecto de 1954 adoptaba una postura amplia frente al crimen de agresión, pues definía como delitos contra la paz y la seguridad de la humanidad: "1) Todo acto de agresión, inclusive el empleo por las autoridades de un Estado de la fuerza armada contra otro Estado para cualquier propósito que no sea la legítima defensa nacional o colectiva o la aplicación de una decisión o recomendación de un órgano competente de las Naciones Unidad". El texto del proyecto puede consultarse en RUEDA FERNÁNDEZ, ob. cit., p. 225. 
modo que otras formas ilícitas del uso de la fuerza armada quedaban por fuera del ámbito de punibilidad de este crimen internacional ${ }^{32}$.

\section{LA CONSAGRACIÓN DEL CRIMEN DE AGRESIÓN EN EL ESTATUTO DE LA CORTE PENAL INTERNACIONAL}

Continuando con el desarrollo del crimen de agresión en el derecho internacional, resulta necesario detenerse en la consagración de este crimen en el Estatuto de la CPI.

La doctrina consultada señala que la mayoría de las delegaciones en la Conferencia de Roma compartían la opinión según la cual la jurisdicción de la CPI se hallaría incompleta si no abarcaba una conducta convencional y consuetudinariamente reconocida como crimen internacional, tal como lo es el crimen de agresión. Es más, en su opinión resultaba ilógico que se pretendiera estatuir una Corte Internacional con competencia sobre los crímenes más graves de trascendencia para la comunidad internacional en su conjunto, pero se dejara de lado el crimen que desde Nuremberg fue catalogado como el crimen internacional supremo ${ }^{33}$.

Estas consideraciones condujeron a que en el artículo 5. ${ }^{\circ}$ del Estatuto de la CPI se otorgara competencia a la Corte para enjuiciar a los responsables por el crimen de agresión. Sin embargo, la imposibilidad de llegar a un acuerdo en torno a su definición y a las condiciones bajo las que la Corte debía ejercer su jurisdicción llevaron a los delegados a aplazar la competencia del Tribunal frente al crimen de agresión hasta tanto se alcanzara un acuerdo sobre estos puntos. En todo caso, debe destacarse que el Estatuto de la Corte Penal Internacional fijó los criterios bajo los cuales habría de adoptarse la definición y las condiciones para el ejercicio de la jurisdicción sobre el crimen de agresión. En particular, el artículo 5..$^{\circ}$ (2) del Estatuto es claro en señalar que estas determinaciones debían ser compatibles con la CNU.

32 La misma postura es sostenida por WERLE, para quien "Con la determinación del concepto de guerra de agresión queda clara y exclusivamente definido el ámbito de los actos de agresión punibles de conformidad con el derecho internacional. Se fija con ello un alto umbral de punibilidad. Actos de agresión de menos intensidad no son punibles, aunque infrinjan la prohibición del uso de la fuerza del art. $2 n .^{\circ} 4$ de la Carta de la ONU [...]. Sin embargo, para una criminalización internacional más amplia falta tanto la práctica internacional como la opinio iuris de la comunidad internacional": WERLE, ob cit., p. 755.

33 SungA, ob. cit., p. 238. "La jurisdicción 'ratione materiae' de la Corte Penal Internacional. Es claro que la mayoría de los Estados compartían el punto de vista de que, en el mundo contemporáneo, fijar una corte penal internacional permanente sobre crímenes de menor magnitud, tales como casos individuales de crímenes de guerra o crímenes de lesa humanidad, sin procurar castigar la beligerancia crearía una extraña anomalía. Como muchos abusos ocurren en el contexto de un conflicto armado, omitir el crimen de agresión en el Estatuto equivaldría en muchos casos a tratar los meros síntomas y evitar las causas patógenas": ibíd., p. 240. 
Las labores para definir el crimen de agresión comenzaron con la "Resolución F" adoptada por los delegados en Roma, la cual estableció una Comisión Preparatoria para trabajar en la definición, así como en las condiciones bajo las cuales la CPI debía ejercer jurisdicción. En el año 2002 la Asamblea de Estados Partes de la CPI estableció un Grupo Especial de Trabajo para el Crimen de Agresión (SWGCA, siglas en inglés), el cual, después de numerosas reuniones entre 2003 y 2009, presentó una definición final en febrero de $2009^{[34]}$.

Finalmente, el 11 de junio de 2010 los delegados de los Estados Partes que asistieron a la 1. ${ }^{\text {a }}$ Conferencia de Revisión del Estatuto de la CPI adoptaron por consenso la Resolución RC/RES. 6, basada en los trabajos del SWGCA, en la que se definió el crimen de agresión en los siguientes términos:

Artículo 8 bis

Crimen de agresión

1. A los efectos del presente Estatuto, una persona comete un "crimen de agresión" cuando, estando en condiciones de controlar o dirigir efectivamente la acción política o militar de un Estado, dicha persona planifica, prepara, inicia o realiza un acto de agresión que por sus características, gravedad y escala constituya una violación manifiesta de la CNU.

2. A los efectos del párrafo 1, por “acto de agresión” se entenderá el uso de la fuerza armada por un Estado contra la soberanía, la integridad territorial o la independencia política de otro Estado, o en cualquier otra forma incompatible con la CNU. De conformidad con la Resolución 3314 (XXIX) de la Asamblea General de las Naciones Unidas, de 14 de diciembre de 1974, cualquiera de los actos siguientes, independientemente de que haya o no declaración de guerra, se caracterizará como acto de agresión:

a) La invasión o el ataque por las fuerzas armadas de un Estado del territorio de otro Estado, o toda ocupación militar, aún temporal, que resulte de dicha invasión o ataque, o toda anexión, mediante el uso de la fuerza, del territorio de otro Estado o de parte de él;

b) El bombardeo, por las fuerzas armadas de un Estado, del territorio de otro Estado, o el empleo de cualesquiera armas por un Estado contra el territorio de otro Estado; 
c) El bloqueo de los puertos o de las costas de un Estado por las fuerzas armadas de otro Estado;

d) El ataque por las fuerzas armadas de un Estado contra las fuerzas armadas terrestres, navales o aéreas de otro Estado, o contra su flota mercante o aérea;

e) La utilización de fuerzas armadas de un Estado, que se encuentran en el territorio de otro Estado con el acuerdo del Estado receptor, en violación de las condiciones establecidas en el acuerdo o toda prolongación de su presencia en dicho territorio después de terminado el acuerdo;

f) La acción de un Estado que permite que su territorio, que ha puesto a disposición de otro Estado, sea utilizado por ese otro Estado para perpetrar un acto de agresión contra un tercer Estado;

g) El envío por un Estado, o en su nombre, de bandas armadas, grupos irregulares o mercenarios que lleven a cabo actos de fuerza armada contra otro Estado de tal gravedad que sean equiparables a los actos antes enumerados, o su sustancial participación en dichos actos.

La disposición transcrita se nutre de diversas fuentes normativas. Así, por ejemplo, las conductas individuales constitutivas del crimen de agresión (planificar, preparar iniciar o ejecutar) son reflejo de la definición de crimen contra la paz prevista en el Estatuto del TMI de Nuremberg. Por su parte, la definición de acto de agresión como "el uso de la fuerza armada por un Estado contra la soberanía, integridad territorial o independencia política de otro Estado", responde en buena parte al texto del artículo 2 (4) de la CNU. Por último, la lista de actos de agresión enumerados en los literales a) a g) del parágrafo 2. ${ }^{\circ}$ es tomada de la Resolución de la AGNU n. ${ }^{\circ} 3314$ de 1974. En consecuencia, debe dársele la razón a TRABAN cuando sostiene que "la definición [del crimen de agresión] se deriva de fuentes preexistentes, por lo que difícilmente refleja un nuevo concepto" 35 .

La definición adoptada en Kampala amplió definitivamente el alcance del crimen de agresión, al establecer como hecho de base no solamente el desarrollo de una guerra de agresión, sino de todo acto de agresión que, de conformidad con sus características, magnitud y gravedad, constituya una infracción a la CNU.

Pese a que el consenso alcanzado en Kampala no está libre de críticas ${ }^{36}$, en particular en lo que se refiere a las condiciones para que la Corte ejerza su competencia sobre

35 Trahan, ob. cit., p. 57.

36 En este punto ver CREEGAN, ob. cit., p. 65, quien resalta la indeterminación existente respecto a cuáles usos de la fuerza son legítimos y cuáles no, pues "the dynamism of state practice is critical in shaping 
el crimen de agresión, no cabe duda de que a partir del mes de junio del año 2010 la comunidad internacional cuenta con una definición consensuada del crimen internacional bajo estudio, que permitirá valorar la legalidad de la conducta de los líderes mundiales que acudan al uso de la fuerza armada en el escenario internacional; logro que no debe ser menospreciado.

\section{LA NATURALEZA DUAL DEL CRIMEN DE AGRESIÓN}

Todos los crímenes de derecho internacional suponen la existencia de un contexto de violencia organizada; circunstancia que es, precisamente, la que potencia las conductas delictivas individuales al rango de atentados contra los valores de la comunidad internacional.

En otras palabras, todos los crímenes internacionales comportan una naturaleza dual ${ }^{37}$, pues están integrados por una conducta individual, tradicionalmente considerada delictiva, que se desarrolla en un contexto de violencia organizada del que, a su vez, hace parte; es esta característica -la macrocriminalidad- la que conduce a que dicha conducta pueda ser considerada un auténtico crimen de derecho internacional ${ }^{38}$.

El crimen de agresión no es la excepción, por el contrario, es en este delito de derecho internacional en el que se advierte con mayor claridad el vínculo entre la conducta individual y el contexto de violencia organizada al que se viene haciendo mención; pues la conducta individual sancionada consiste, precisamente, en desencadenar el ejercicio sistemático de violencia por parte de un Estado contra otro. En efecto, la conducta individual objeto de punición en el crimen internacional de agresión consiste en planificar, preparar, iniciar o realizar un acto de agresión, esto es, en el uso de la fuerza armada por parte de un Estado contra la integridad territorial o la independencia política de otro en contravención de la CNU. Como se observa, en el crimen de agresión el contexto de violencia organizada obedece a la conducta individual, a diferencia de los crímenes contra la humanidad en los que la conducta individual accede a dicho contexto.

Las anteriores reflexiones anticipan una distinción que resulta básica para la adecuada comprensión del crimen de agresión; a saber: una cosa es el acto de agresión y

the legitimate uses of force"; además, señala el autor que hay una necesidad de evaluación política del acto, por ello, se han propuesto unos filtros (gatekeepers) para activar la jurisdicción de la CPI, ya sea por parte del CSNU, la AGNU o la CIJ, todo lo cual conduce a la conclusión de que no se ha logrado una definición satisfactoria en el ECPI. Para este autor la CPI debería incluso perder su jurisdicción sobre el crimen de agresión, ya que, según él, "use of force should remain a question of customary law, rather than international criminal law" (p. 82).

37 KAI AmBos. El crimen de agresión después de Kampala. LUCAS TASSARA (TRAD.). Madrid, Dykinson, 2011, p. 39.

38 Werle, ob. cit., p. 248. Ambos. El crimen de agresión después de Kampala, cit., p. 39. 
otra distinta la comisión del crimen de agresión, aun cuando esta última suponga la efectiva ocurrencia de un acto de agresión. Sobre el particular, la doctrina consultada coincide en señalar, y así se desprende del tenor literal del artículo 8 bis del ECPI, que la verificación de un acto de agresión no supone automáticamente responsabilidad penal por la comisión de un crimen de agresión, pues este último solo se configura ante la conducta individual de quienes efectivamente conducen el Estado consistente en planificar, preparar, iniciar o realizar un acto de agresión que por sus características, gravedad y escala constituya una violación manifiesta a la CNU. Como puede observarse, la norma en comento abarca como supuesto típico del crimen de agresión toda intervención de quienes efectivamente dirigen un Estado en el desarrollo de un acto de agresión de las características antes anotadas; independientemente de que dicha intervención tenga lugar antes o durante la ejecución de dicho acto ${ }^{39}$.

$\mathrm{Al}$ respecto, $\mathrm{AmBOS}$ sostiene que resultaba innecesario consagrar como verbo rector del crimen de agresión la intervención durante las etapas de planeación y preparación, pues dado que el acto de agresión efectivamente debe ejecutarse para que se estructure el crimen de agresión -en atención a consideraciones que se analizaran más adelante-, ningún sentido tiene castigar actos preparatorios cuya sanción ya estaría comprendida en la conducta de iniciar o realizar el acto de agresión ${ }^{40}$. Coincidimos con АмBos en cuanto a que el crimen de agresión supone la efectiva ocurrencia del acto de agresión, sin embargo, consideramos que la referencia a la intervención en las etapas de planeación y preparación no resulta redundante o innecesaria, pues bien puede ocurrir que un dirigente político o militar intervenga activamente en la ideación de un plan de agresión, pero al momento en que se lleva a cabo carezca del control efectivo sobre las estructuras del Estado que antes dominaba; circunstancia que, conforme a la definición consagrada en el artículo 8 bis, no lo eximiría de responsabilidad penal por la comisión de un crimen de agresión, pues al momento de su intervención en el devenir del crimen gozaba de las calidades exigidas en la norma internacional. No obstante, debe aceptarse que el ejemplo planteado difícilmente tendrá ocurrencia y que por regla general los dirigentes que participan en la planeación o preparación de un acto de agresión son los mismos que ordenan su inicio y dirigen su realización.

\section{EL ACTO DE AGRESIÓN COMO FUNDAMENTO DEL CRIMEN DE AGRESIÓN}

A continuación nos detendremos en el estudio del acto de agresión en tanto fundamento del crimen de agresión, en particular, se analizará la definición del concepto incorporada en el artículo 8 bis y los supuestos de actos de agresión enunciados en los literales a) a g) del parágrafo 2. ${ }^{\circ}$ de dicha disposición.

39 Cfr. Corredor Carvajal, ob. cit., pp. 62 ss.

40 Амвоs. El crimen de agresión después de Kampala, cit., pp. 52 ss. 
Conforme lo prevé el mentado parágrafo 2. ${ }^{\circ}$, la agresión supone el uso de la fuerza armada por parte de un Estado en contra de la soberanía, la integridad territorial o la independencia política de otro Estado; finalidades meramente enunciativas, pues el propio artículo dispone que todo uso de la fuerza armada con miras a la consecución de un propósito incompatible con la CNU supone un acto de agresión.

La señalada definición es fiel copia del concepto de agresión consagrado en el artículo 1..$^{\circ}$ del anexo de la Resolución 3314 de la AGNU, adoptada el 14 de diciembre de 1974, en consecuencia, deja por fuera del concepto de acto de agresión toda forma de coacción en el ámbito internacional distinta al empleo de la fuerza armada y limita el concepto a la acción de los Estados.

Pese a que algunas delegaciones durante la conferencia de revisión abogaban por extender el concepto de acto de agresión a todo tipo de injerencia de un Estado sobre la autonomía o soberanía de otro ${ }^{41}$, la inmensa mayoría de las delegaciones coincidieron en que el mandato del artículo 5..$^{\circ}$ del ECPI imponía adoptar una definición de acto de agresión compatible con la CNU; definición que no podía ser en esencia distinta a la ya consagrada en la referida Resolución 3314.

Mayor debate, cuando menos en la doctrina, ha suscitado la vinculación del acto de agresión a una acción estatal, lo que excluye la posibilidad de que dirigentes de organizaciones no estatales puedan incurrir en un crimen de agresión. Así, por ejemplo, KREß y HoltzendorfF sostienen que, dado que el Consejo de Seguridad ha catalogado la acción violenta de ciertas organizaciones transnacionales como un atentado contra la paz internacional y considerado su accionar como un ataque armado para los propósitos del ejercicio de la legitima defensa - art. 51 CNU-, no existe ningún motivo para no extender la responsabilidad penal por la comisión de un crimen de agresión a los dirigentes de este tipo de organizaciones ${ }^{42}$. También AMBos critica que solo la acción estatal pueda ser considerada un acto de agresión, pues tal limitación, en su criterio, va en contravía del enfoque actual del derecho penal internacional, conforme al cual no son las características del autor sino la lesividad del acto la que otorga al crimen de agresión su relevancia internacional ${ }^{43}$.

41 En particular, la delegación de Cuba, en su condición de Estado observador durante la conferencia de revisión, declaró lo siguiente tras la aprobación de la Resolución RC/Res. 6 sobre el crimen de agresión: "La delegación cubana reitera su opinión en cuanto a la necesidad de haber logrado una definición del crimen de agresión genérica y no limitada sólo al uso de la fuerza armada por un Estado, dejando de lado otras formas de agresión que también pueden vulnerar la soberanía, la integridad territorial o la independencia política de otros Estados". Anexo Ix a la Resolución RC/Res. 6. Declaraciones formuladas por Estados observadores después de la aprobación de la Resolución RC/Res. 6 sobre el crimen de agresión. En: Ambos. El crimen de agresión después de Kampala, cit., p. 158.

42 Claus Kreß y Leonie Von HoltzendorfF. "The Kampala Compromise on the Crime of Aggression". Journal of International Criminal Justice, vol. 8, 2010, p. 1190.

43 Амвоs. El crimen de agresión después de Kampala, cit., p. 45. 
Por nuestra parte, consideramos que el carácter estatal del ejercicio de la fuerza armada no es un requisito sine qua non del acto de agresión, de modo que de lege ferenda nada obstaría para que se admitiera la responsabilidad penal por un crimen de agresión de los dirigentes de organizaciones armadas no estatales. No obstante, debe reconocerse que por lo general el uso de la fuerza armada por parte de dichas organizaciones contra la población civil de un Estado, e inclusive contra sus fuerzas armadas, encuentra adecuación en otras categorías de crímenes internacionales ${ }^{44}$.

Otro caso a considerar es el de los denominados "cuasi-Estados", movimientos separatistas que bajo el criterio de la libre determinación controlan un determinado territorio y ejercen funciones estatales. La doctrina consultada expone criterios a favor y en contra en cuanto a la aplicación de la prohibición del uso de la fuerza frente estos territorios ${ }^{45}$. Como criterios a favor se señala la integridad de la prohibición del uso de la fuerza, pues un trato diferente frente a los conflictos internacionales (Estado Estado) y no internacionales (Estado - cuasi-Estado) sería altamente arbitrario debido al carácter meramente político del reconocimiento estatal. Además, dicha prohibición de ninguna manera ha sido instaurada para proteger Estados completamente formados, sino más bien para proteger bienes jurídicos de carácter internacional como la paz y la seguridad ${ }^{46}$.

Otra discusión trascendente que suscita la definición consagrada en el parágrafo 2. ${ }^{\circ}$ del artículo 8 bis es si el listado de actos de agresión señalado en el los literales a) a g) tiene carácter taxativo o meramente enunciativo. En otras palabras, si cabe identificar como fundamento del crimen de agresión otros actos de agresión distintos a los enunciados en los mencionados literales.

Esta cuestión divide a la doctrina consultada. Así por ejemplo, AmBos afirma que la lista de actos enunciados en el parágrafo $2 .^{\circ}$ no puede ser abierta ni semi-abierta, sino que debe ser considerada exhaustiva. Como fundamento de su posición, sostiene que el artículo 8 bis no consagra una cláusula inclusiva de hechos similares, como sí la prevé el artículo $7 .^{\circ}(1, \mathrm{k})$ del ECPI en relación con los crímenes contra la humanidad; además, considera que una interpretación extensiva de los supuestos de agresión atentaría contra el mandato de lex certa en tanto imperativo integrante del principio de legalidad ${ }^{47}$. En igual sentido, CORREDOR considera que el principio de legalidad impide que el carácter meramente enunciativo del listado de actos de

44 En efecto, las organizaciones armadas transnacionales por lo general se valen del terrorismo como método de lucha; práctica que, aunada a las circunstancias previstas en el ECPI, puede llegar a ser considerada constitutiva de crímenes de guerra o crímenes contra la humanidad.

45 Alexander G. Wills. "The crime of aggression and the resort to force against entities in statu nascendi". Journal of International Criminal Justice, vol. 10, 2012.

46 WILLS, ob. cit., p. 104.

47 Амвоs. El crimen de agresión después de Kampala, cit., p. 44. 
agresión reconocido en la Resolución 3314 pueda extenderse al ámbito penal; de modo que únicamente los hechos descritos en los literales antes citados pueden considerarse actos de agresión para los propósitos de la responsabilidad penal en el plano internacional ${ }^{48}$. En igual sentido SÁNCHEZ, para quien el principio de legalidad impide que los demás actos que por sus características puedan asimilarse a actos de agresión sean valorados para el propósito de establecer la responsabilidad penal por el crimen de agresión ${ }^{49}$.

Por el contrario, KREß y HoltzendoRfF afirman que la redacción del artículo 8 bis permite que hechos distintos a los señalados en el listado del parágrafo $2 .^{\circ}$ sean valorados como actos de agresión. Al respecto, consideran que el citado parágrafo consagra una definición general del acto de agresión y que el listado al que antecede únicamente tiene como finalidad brindar pautas para la interpretación de dicha definición; lo que no es óbice para que otros hechos puedan ser considerados actos de agresión en el escenario del derecho internacional penal, siempre que reúnan las condiciones generales previstas en el parágrafo ${ }^{50}$. Esta conclusión es compartida por TraHAN, quien además sostiene que el Grupo Especial de Trabajo sobre el Crimen de Agresión ${ }^{51}$-SWGCA por sus siglas en inglés- optó tras largas deliberaciones por reconocer un carácter semi-abierto al listado al que se viene haciendo mención, conforme al cual hechos distintos a los allí enunciados pueden ser considerados actos de agresión a condición de que reúnan las exigencias previstas en el parágrafo 2 . $^{\circ}$ opción que en criterio de la autora no resulta lesiva del principio de legalidad ${ }^{52}$.

Consideramos que existen suficientes razones para concluir que el listado de actos de agresión previsto en el parágrafo $2{ }^{\circ}$ del artículo 8 bis es meramente enunciativo y no limita el universo de casos que pueden configurar un acto de agresión para los efectos del crimen internacional de agresión. En primer lugar, porque el parágrafo 2. ${ }^{\circ}$ claramente indica que el listado de actos de agresión allí enunciado responde a las previsiones de la Resolución 3314, en la que expresamente se señala que "la enumeración de los actos mencionados anteriormente no es exhaustiva" 53 ; lo que implicaría que el carácter enunciativo del listado, reconocido en la mentada resolución, también es predicable del consagrado en el artículo 8 bis.

48 Corredor CARvajal, ob. cit., p. 120.

49 Raúl EduARdo SÁnchez SÁnchez. "La definición del crimen de agresión”. Derecho Penal Contemporáneo n. $^{\circ} 39,2012$.

50 Kreß y Von HoltZendorfF, ob. cit., p. 1191.

51 Creado por la Asamblea General de la CPI y cuyos trabajos sirvieron de base para el acuerdo alcanzado en Kampala.

52 Trahan, ob. cit., p. 59.

53 Art. 4. ${ }^{\circ}$ del anexo de la Resolución 3314 del 14 de diciembre de 1974, adoptada por la Asamblea General de las NU. 
Pero más allá de la expresa referencia a la Resolución 3314, lo cierto es que la redacción del artículo 8 bis parece indicar que el listado al que se viene haciendo mención no limita el catálogo de hechos que pueden constituir un acto de agresión. Al respecto, adviértase que, a diferencia de la definición de crímenes contra la humanidad, en la que se sanciona la comisión de una conducta individual que se incorpora a un ataque contra la población civil, la definición del crimen de agresión consagra como conducta punible la intervención en la fase previa o ejecutiva de un acto de agresión, es decir, todos los elementos del crimen de agresión están descritos en el parágrafo $1 .{ }^{\circ}$. En otras palabras, conforme a la definición consagrada en el parágrafo $1 .^{\circ}$ del artículo 8 bis, la comisión del crimen de agresión no supone la realización de uno de los actos de agresión enunciados en el parágrafo $2{ }^{\circ}$, sino de un acto de agresión en términos generales. Como se observa, el parágrafo $2 .^{\circ}$ del artículo 8 bis no adiciona la conducta constitutiva del crimen internacional de agresión en el sentido de que establezca un elemento adicional de este crimen internacional; únicamente define lo que debe entenderse como acto de agresión en el ámbito del derecho internacional penal.

De lo expuesto parece acertado concluir que el listado previsto en el parágrafo $2{ }^{\circ}$ no es taxativo, sino meramente ejemplificativo del concepto de acto de agresión, cuyos elementos esenciales están definidos en la primera parte del señalado parágrafo.

En todo caso, conviene precisar que cualquier hecho al que pretenda dársele la denominación de acto de agresión como fundamento de responsabilidad penal debe reunir las características enunciadas en los parágrafos $1 .^{\circ}$ y $2 .^{\circ}$, esto es, debe tratarse del uso de la fuerza armada por un Estado en contra de otro de forma incompatible con la CNU (art. 8 bis 2), que por sus características, gravedad y escala constituya una violación manifiesta a dicho estatuto.

Además, la presencia del listado de actos de agresión al que se viene haciendo referencia impone que otros hechos a los que pretenda dárseles tal denominación respondan al criterio de eiusdem generis, esto es, debe tratarse de hechos similares en su naturaleza y magnitud a aquellos expresamente reconocidos como actos de agresión en el parágrafo $2 .^{\circ}$ del artículo 8 bis $^{54}$.

En este punto debe reconocerse que el listado consagrado en la Resolución 3314, trasladado al artículo 8 bis, contiene hechos de la más diversa naturaleza, es más, algunos ni siquiera suponen el uso de la fuerza armada en el sentido tradicional de la expresión; así sucede, por ejemplo, con el literal f) en el que se consagra como

54 Para una completa exposición del criterio eiusdem generis y su aplicación en frente al catálogo de conductas constitutivas de crímenes contra la humanidad, ver IRIS HAENEN. "Classifying acts as crimes against humanity in the Rome Statute of the International Criminal Court". German Law Journal, vol. 14, n. $^{\circ}$ 7, 2013,pp. 796-822. 
acto de agresión la acción de un Estado consistente en permitir que otro emplee su territorio para lanzar un acto agresión contra un tercer Estado.

No obstante, consideramos que sí es posible establecer un común denominador de los actos de agresión enunciados en el parágrafo $2 .^{\circ}$, que sirva como criterio para determinar si un hecho puede o no ser considerado como un acto de agresión para los propósitos del crimen internacional de agresión. Dicha característica común está representada en el hecho de que todos los actos enunciados en el mencionado parágrafo tienen la potencialidad de provocar una respuesta armada, en principio lícita, por parte del Estado agredido, lo que, a su vez, puede dar lugar al desarrollo de un conflicto bélico y, por esa vía, amenazar los valores de la paz, seguridad y bienestar de la comunidad internacional.

Así las cosas, estimamos que no existe óbice para considerar como acto de agresión, para los efectos de la comisión del crimen de agresión, la acción de un Estado consistente en contratar los servicios de piratas informáticos para que atenten contra la infraestructura del Estado agredido; acción que comprende una nueva forma de uso de la fuerza, constituye una infracción manifiesta de la CNU y, además, se compadece con el criterio eiusdem generis, pues legitima el uso de la fuerza armada por parte del Estado agredido ${ }^{55}$.

Esta conclusión, aunque con distinta fundamentación, también es expuesta por Ambos, quien con acertado criterio considera que un ataque informático puede ser equiparado, bajo ciertas circunstancias, a un ataque militar y, en consecuencia, constituir un acto de agresión. Esta afirmación, valga aclararlo, no contradice el rechazo de este autor al criterio del eiusdem generis, pues una interpretación teleológica del concepto "uso de fuerza armada" comprende los ataques informáticos que producen consecuencias similares a los ataques militares tradicionalmente recogidos por el derecho internacional humanitario. En otras palabras, para Амвоs no es necesario aceptar el carácter enunciativo del listado de actos de agresión en el artículo 8 bis (2), para considerar los ataques informáticos como actos equiparables al uso de la fuerza armada recogida en los literales b) y d) de dicha norma.

Al respecto, afirma el citado autor:

En cuanto a los actos enumerados por la norma -art. 8 bis-, solo aquellos contemplados en los apartados (b) y (d) pueden ser llevados a cabo a través de un ataque informático. El supuesto del apartado (b) exige, en su segunda alternativa, el "empleo de cualesquiera armas" contra el territorio de otro Estado, entonces no incluiría a las herramientas típicas que se utilizan para

55 En sentido contrario CORREDOR, para quien el caso propuesto escapa del ámbito de punibilidad del crimen de agresión. CORREDOR CARVAJAL, ob. cit., p. 119. 
realizar un ataque cibernético (e.g., mediante gusanos o virus informáticos). Sin embargo, un abordaje tan estricto iría en contra de la interpretación más flexible de la CIJ en su opinión sobre armas nucleares citada anteriormente ${ }^{56}$, y en rigor de verdad no hay ningún motivo convincente para excluir de la provisión a los ataques cibernéticos si causan un daño igual o similar que las armas convencionales. En todo caso, el apartado (d), que exige un "ataque por las fuerzas armadas", permite una interpretación más amplia que abarque los ataques cibernéticos llevados a cabo por miembros de las fuerzas armadas contra las fuerzas de otro Estado. De hecho, un ataque cibernético en un país desarrollado, que se basa fuertemente en sus redes computarizadas para operar su infraestructura (e.g., control del tráfico, suministro del agua y de la electricidad) y sus fuerzas armadas (e.g., sistema de defensa aéreos, jets de combate modernos, equipos de comunicación o drones) puede llevar a la inoperatividad completa o parcial del sistema respectivo. Por cierto, en términos de resultado es indistinto si las fuerzas armadas resultan inoperables por los ataques "convencionales" de otras fuerzas armadas o por ataques cibernéticos $^{57}$ (resaltado fuera de texto).

\section{EL UMBRAL DE GRAVEDAD Y ANTIJURIDICIDAD DEL ACTO DE AGRESIÓN COMO FUNDAMENTO DE LA RESPONSABILIDAD PENAL INDIVIDUAL}

No todo uso ilícito de la fuerza armada por parte de un Estado contra otro da lugar a responsabilidad penal bajo la forma de un crimen de agresión; en tal sentido el parágrafo $2{ }^{\circ}$ del artículo 8 bis expresamente dispone que solo los actos que por sus características, gravedad y escala supongan una violación manifiesta de la CNU constituyen actos de agresión para los efectos del crimen de agresión ${ }^{58}$.

Esta cláusula de umbral de gravedad se ve reforzada por lo dispuesto el anexo III de la Resolución RC/Res. 6 del 11 de junio de 2010, en el que se incorporaron distintos entendimientos frente a las enmiendas al Estatuto de Roma relativas al crimen de agresión.

En particular, el numeral 7. ${ }^{\circ}$ del señalado anexo claramente establece que la calificación de un acto de agresión como una violación manifiesta de la CNU necesariamente exige de la concurrencia de los atributos de características, gravedad y escala; de modo que "ninguno de los elementos puede bastar por sí solo para satisfacer el criterio de la violación manifiesta".

56 Supra nota 26.

57 Kал Aмвоs. Responsabilidad penal internacional en el ciberespacio. Bogotá, Universidad Externado de Colombia, 2014.

58 Cfr. Ambos. El crimen de agresión después de Kampala, cit., p. 39 y 40. 
Al respecto, KREß y HOLTZENDORFF explican que el entendimiento consagrado en el mentado numeral 7. ${ }^{\circ}$ pretende excluir del ámbito del crimen de agresión, aquellos casos de uso de la fuerza armada que no reúnan la "suficiente seriedad"59 o cuya ilicitud no se advierta con claridad. En particular, la referencia a la gravedad y escala impide que el empleo de la fuerza armada de menor entidad, aunque ilícito, pueda ser considerado un acto de agresión en tanto elemento del crimen de agresión. Por su parte, la remisión a las características del acto hace referencia a su ilicitud conforme al derecho internacional, de modo que aquellas "zonas grises" 60 en las que se duda de la legalidad del uso de la fuerza estén descartadas como supuesto del crimen internacional objeto de este estudio.

La concurrencia de estos tres atributos - características, gravedad y escala- debe conducir al convencimiento de que el uso de la fuerza armada en un determinado caso constituyó una violación manifiesta a la CNU; entendiendo por violación manifiesta, siguiendo los lineamientos del artículo 46 (2) de la Convención de Viena sobre el Derecho de los Tratados, aquella que "resulta objetivamente evidente para cualquier Estado que proceda en la materia conforme a la práctica usual y de buena fe"61. Sin embargo, esta especial calificación ha sido objeto de críticas: por ejemplo, PAULUS señala que si se parte de la definición del concepto en inglés que trae el Oxford English Dictionary ("clearly revealed to the eye, mind or judment;... obvious), deberá concluirse que el término "manifiesto" nada aporta a la conducta objeto del crimen de agresión, pues "lo que es obvio para uno es completamente oscuro para otro, en particular en derecho internacional"62. De igual modo, POTTER indica que "manifiesta" se refiere a una obvia o clara violación de la CNU, criterio que se establece mirando su escala, gravedad y características, por lo tanto, "manifiesta" no añade otra cosa que confusión a la definición del crimen ${ }^{63}$. Algunos delegados también resaltaron la redundancia existente en la exigencia de que la violación sea "manifiesta", pues es claro que la CPI solo debe ocuparse de los más serios crímenes en el ámbito internacional. Aún más, el preámbulo de la Resolución 3314 considera que "la agresión constituye la forma más grave y peligrosa del uso ilegítimo de la fuerza". Por estas razones el SWGCA llegó a considerar otros términos en reemplazo de "manifiesta" como "flagrante" sin llegar a ser consagrados en la definición final, pues parecían no aportar la precisión buscada ${ }^{64}$.

59 KREß Y HOLTZENDORFF, ob. cit., p. 1193.

60 KREß Y HOLTZENDORFF, ob. cit., pp. 1206 y ss.

61 Convención de Viena sobre el Derecho de los Tratados. U.N. Doc A/CONF.39/27 (1969), 1155 U.N.T.S. 331. En todo caso, debe aclararse que el concepto de violación manifiesta consagrado en la Convención hace referencia al derecho interno.

62 Citado por O'Connell y NiYAZMATOv, ob. cit., p. 203.

63 Ibíd., pp. 203 y 204

64 Ibíd., p. 204. 
Los demás calificadores del acto de agresión -características, escala y gravedad-son también objeto de cuestionamientos por la doctrina. Así por ejemplo, para PAULUS “el término 'características' es el más indeterminado en el artículo 8bis y ‘casi sin significado', lo que deja en total discreción a la Corte para decidir si las características del crimen ameritan persecución bajo el artículo 8bis" 65 . En cuanto a la gravedad, el citado autor anota que no está muy claro si se refiere a la cantidad de fuerza utilizada, a la destrucción causada, al nivel de violación de las normas internacionales o a algo más. La misma indeterminación puede reflejarse en el término "escala"66.

Ahora bien, otro interrogante que suscita la incorporación del señalado umbral de gravedad (que el acto de agresión constituya una violación manifiesta a la CNU) es si se trata de un condicionamiento a la competencia de la CPI o si, por el contrario, nos hallamos ante un elemento inherente a la noción de crimen de agresión; de modo que deba ser valorado por otras instancias judiciales que, en ejercicio del principio de jurisdicción universal, pretendan arrogarse competencia para enjuiciar este crimen.

Al respecto, conviene precisar que en el Estatuto de la CPI y, en especial, en la definición de los crímenes de competencia de la Corte, la referencia a un determinado umbral de gravedad se efectúa en los dos sentidos antes indicados, esto es, como elemento esencial de algunos crímenes internacionales o, en otros casos, como requisito o condicionamiento para que la Corte ejerza su competencia sobre un determinado hecho. Así por ejemplo, en tratándose de los crímenes contra la humanidad el Estatuto reconoce como elemento esencial de su definición la existencia de un contexto de violencia, el cual está representado por el desarrollo de un ataque generalizado o sistemático contra la población civil; de modo que solo las conductas enunciadas en el artículo 7. ${ }^{\circ}$ (2) del ECPI que se encuentren incorporadas en el señalado contexto de violencia podrán ser consideradas auténticos crímenes contra la humanidad. En razón de lo expuesto, resulta acertado concluir que la significativa gravedad y magnitud es una condición esencial de los crímenes contra la humanidad y no un simple condicionamiento para que sean enjuiciados por parte de la CPI. Por el contrario, la configuración de otras categorías de crímenes internacionales, como los crímenes de guerra, no está supeditada a este umbral de gravedad, aun cuando la competencia de la CPI sí lo esté. En efecto, en tratándose de los crímenes de guerra el artículo $8 .{ }^{\circ}$ del Estatuto de la CPI claramente establece: "La Corte tendrá competencia respecto de los crímenes de guerra en particular cuando se cometan como parte de un plan o política o como parte de la comisión a gran escala de tales crímenes" ${ }^{67}$.

65 Ibíd., p. 204.

66 Ibíd., p. 204.

67 En relación con el alcance de la disposición transcrita, afirma AmBos: "el requisito adicional contenido en el art. 8 de que la comisión sea 'parte de un plan o política o como parte de la comisión [...] a gran escala' representa una limitación no exigida por el derecho internacional humanitario consuetudinario y contractual. Sin embargo, éste es inofensivo, dado que la expresión 'en particular' -al contrario de la formulación 'sólo' favorecida por algunos Estados- deja en claro que no se trata de un requisito 
En lo que respecta al crimen de agresión compartimos la opinión de aquellos doctrinantes que a partir del análisis de los trabajos preparatorios del SWGCA consideran que la significativa magnitud y gravedad del acto de agresión, así como su carácter de violación manifiesta a la Carta de las Naciones Unidas, constituyen elementos del crimen de agresión en los términos del artículo 8 bis del Estatuto de la CPI, y no un mero condicionamiento a la competencia de la Corte $^{68}$. En este punto, coincidimos con АмBos en cuanto a que la existencia de un umbral alto de gravedad resulta necesaria para evitar la "trivialización" del crimen de agresión, así como en que determinadas hipótesis de uso de la fuerza armada, aun cuando no respondan a la legítima defensa ni a la autorización del Consejo de Seguridad, no necesariamente resultan manifiestamente contrarias a la CNU y, por tanto, no deben ameritar responsabilidad penal ${ }^{69}$.

No obstante, debe criticarse la redacción de la cláusula de umbral de gravedad a la que se viene haciendo mención, pues parecería supeditar el carácter de violación manifiesta a la CNU del acto de agresión a su magnitud y escala; pese a tratarse de aspectos no necesariamente vinculados. Es más, se trata de puntos llamados a ser valorados en planos distintos, pues la magnitud y escala, se reitera, hace referencia a consideraciones ontológicas o fácticas, en tanto que la violación manifiesta a la CNU es una apreciación de carácter eminentemente normativo.

Así, por ejemplo, una intervención armada en el territorio de un Estado que pretenda evitar la comisión de un genocidio o de crímenes contra la humanidad, sin que medie autorización del Consejo de Seguridad, no podrá ser considerada una violación manifiesta a la CNU, ni, por tanto, un acto de agresión que dé lugar a responsabilidad penal para los dirigentes del Estado interventor; aun cuando se trate del uso de la fuerza a gran escala y de significativa gravedad ${ }^{70}$.

imprescindible, sino solamente de 'factors wich should will taken into account'. Tampoco se trata aquí, por lo demás, de elementos del tipo, sino únicamente de una norma de competencia judicial": KAI Ambos. La Parte General del Derecho Penal Internacional. Bases para una elaboración dogmática. Ezequiel Malarino (TRAD.). Uruguay, Konrad-Adenauer-Stiftung, 2005, p. 406.

68 Corredor CARVAJal, ob. cit., pp. 86 y 87. y Ambos. El crimen de agresión después de Kampala, cit., pp. 39 y 40.

69 Ambos. El crimen de agresión después de Kampala, cit., p. 40. En lo que hace a los usos legítimos de la fuerza incluso por fuera de los supuestos previstos en la CNU, ver CREEGAN, OB. CIT., quien contempla, tal vez de forma demasiado amplia, las intervenciones humanitarias, la legítima defensa anticipada, la defensa contra agentes no estatales, la prevención de la propagación de un conflicto, la libre determinación de los pueblos y la restauración de un régimen democrático como usos legítimos de la fuerza.

70 En lo que respecta a la doctrina de la intervención humanitaria y el crimen de agresión, debe señalarse que la delegación de Estados Unidos durante la conferencia de Kampala propuso que las intervenciones humanitarias quedaran expresamente excluidas del ámbito del crimen de agresión, propuesta que finalmente no fue adoptada. Sin embargo, coincidimos con KREß y HoLTZENDORFF en cuanto a que la negativa de la Conferencia a incorporar el texto propuesto por los norteamericanos no obedeció a diferencias sustanciales sino a la inconveniencia de una modificación de tal entidad ad portas de la finalización de la Conferencia. KREß y HolTZENDORFF, ob. cit., p. 1205. 


\section{IX. ¿LA DEFINICIÓN DEL CRIMEN DE AGRESIÓN INTRODUCE UNA NUEVA DISTINCIÓN DE ACTOS DE AGRESIÓN EN EL DERECHO INTERNACIONAL?}

Otro interrogante que suscita la incorporación de la cláusula de gravedad a la que se viene haciendo referencia es si el artículo 8 bis establece una nueva distinción en el derecho internacional, entre actos de agresión que constituyen violaciones manifiestas a la CNU y, por tanto, pueden servir de base para la responsabilidad penal por el crimen de agresión y, por el contrario, actos de agresión que no constituyen una violación manifiesta a dicho estatuto y carecen de trascendencia en lo que respecta a la responsabilidad penal de los dirigentes del Estado agresor.

Una lectura exegética del mencionado artículo da lugar a pensar en que en efecto se reconoce la existencia de actos de agresión que no constituyen una violación manifiesta a la CNU y actos que agresión que sí reúnen tal condición; siendo estos últimos los que darían lugar a que se valorara la responsabilidad penal de los dirigentes del Estado agresor por la comisión de un crimen de agresión. Sin embargo, esta hermenéutica ignora que la Resolución 3314 expresamente establece que la agresión constituye "la forma más grave y peligrosa de uso ilegitimo de la fuerza", así como que el artículo 39 de la CNU confiere al Consejo de Seguridad la facultad de determinar la existencia de un acto de agresión, sin hacer referencia a la distinción arriba indicada.

Como puede advertirse, no parece coherente que la agresión se defina como "la forma más grave y peligrosa del uso de la fuerza" cuyo reconocimiento da lugar a la activación del Sistema de Seguridad Colectiva de la ONU, y simultáneamente se reconozca una forma de agresión de menor entidad y trascendencia jurídica, cuya comisión no da lugar a responsabilidad penal en los términos del Estatuto de la CPI.

Consideramos que si se valora la definición de acto de agresión contenida en la Resolución 3314 de la AGNU y las consecuencias que se derivan de la declaración de un acto de agresión por parte del Consejo de Seguridad de la ONU, puede válidamente concluirse que solo existe una categoría de acto de agresión, esto es, el uso de la fuerza armada de significativa gravedad y escala que, a su vez, constituye una violación manifiesta a la CNU.

En otras palabras, el artículo 8 bis del Estatuto de la CPI no establece una graduación de los actos de agresión, sino que refuerza el hecho de que el uso de la fuerza armada en el escenario internacional, para ser considerado un acto de agresión, debe reunir cierta gravedad y escala y, adicionalmente, constituir una violación manifiesta a la $C N U$; de modo que el uso de la fuerza armada que no reúna tales condiciones, aun cuando sea ilícito a la luz del derecho internacional, no será considerado un acto de 
agresión ni dará lugar a responsabilidad penal para los dirigentes del Estado que lo desarrolló por la comisión de un crimen de agresión ${ }^{71}$.

Adicionalmente, interpretar que existen actos de agresión que no resultan manifiestamente contrarios a la CNU tendría un efecto perverso en la prohibición del uso de la fuerza armada, pues si tales actos no dan lugar a responsabilidad penal, tampoco se advierte motivo para que activen el Sistema de Seguridad Colectiva de las $\mathrm{NU}^{72}$.

En conclusión, consideramos que el umbral de gravedad previsto en el artículo 8 bis no fue establecido para categorizar los actos de agresión -entre aquellos que constituyen una violación manifiesta a la CNU y aquellos que no-, sino para subsanar la ambigüedad de la norma primaria de prohibición del uso de la fuerza.

En todo caso, e independientemente de la posición que se adopte, lo cierto es que la responsabilidad penal por el crimen de agresión está supeditada a un uso de la fuerza armada de significativa entidad y que por sus propósitos o condiciones se revele como una violación manifiesta a la CNU.

Por último, debe indicarse que el umbral de gravedad al que se viene haciendo mención es predicable de todos los actos de agresión enunciados tras el parágrafo $2{ }^{\circ}$ del artículo 8 bis; razón por la cual debemos apartarnos de lo sostenido por CORREDOR en el sentido de que el bombardeo, en cuanto modalidad de acto de agresión, no deben reunir ninguna condición de gravedad y escala para ser considerado como fundamento del crimen de agresión ${ }^{73}$. Si bien algunos autores, como KrEß, dudan de que los actos descritos en los literales (c) (bloqueo) y (e) (no retiro de las tropas) del artículo 3 puedan, por regla general, alcanzar el umbral de gravedad requerido para el crimen de agresión 74 .

\section{EL CRIMEN DE AGRESIÓN COMO CRIMEN DE DIRIGENTES}

La definición alcanzada en Kampala limita la posibilidad de comisión del crimen de agresión a los actores estatales, pues el parágrafo $1 .^{\circ}$ del artículo 8 bis claramente establece que será responsable por este punible internacional quien se encuentre "en

71 En contra CORREDOR CARVAJAL, ob. cit., p. 93.

72 Una posición similar es sostenida por ANDREAS PAULus. "Second Thoughts on the Crime of Aggression". The European Journal of International Law, vol. 20, n. ${ }^{\circ}$ 4, 2010, p. 1124, el cual, a diferencia de quien escribe, cuestiona la existencia misma del crimen de agresión en el derecho internacional consuetudinario y la conveniencia de su incorporación en el ECPI.

73 Corredor Carvajal, ob. cit.,p. 107, quien sobre este punto sostiene: "A pesar de la existencia de los criterios de gravedad y escala o incluso de violación manifiesta de la CNU, un umbral de bombardeos no es exigido por la norma - haciendo mención al art. 8 bis. (2) (b). Así entonces, un solo bombardeo efectuado por las fuerzas armadas de un Estado podría ser suficiente para hablar de agresión".

74 Citado por O’CONnEll y NiYAzMatov, ob. cit., p. 200. 
condiciones de controlar o dirigir efectivamente la acción política o militar de un Estado". En opinión de AмBos, este requisito va en contra del proceso de humanización del derecho penal internacional, conforme al cual la definición de los crímenes internacionales estará determinada no por el actor sino por el injusto (wrongfulness) del acto $^{75}$.

En cuanto a las características que deben reunir los responsables por la comisión de un "crimen de agresión", la definición del artículo 8 bis exige que detenten el control o la dirección efectiva sobre el aparato gubernamental o militar de un Estado, es decir, la mera titularidad de un cargo honorífico o sin posibilidad real de decisión no cualifica al sujeto como posible autor de un crimen de agresión, en otras palabras, se exige un control de facto. Adicionalmente, el artículo establece un umbral más alto al de la mera "influencia política" consagrado en el Estatuto del TMI; influencia que ampliaría al extremo el ámbito de aplicación subjetivo de este delito, más aun en las democracias participativas. Como bien lo señala Aмвоs, "La responsabilidad penal requiere algo más que la mera influencia, a saber, el control efectivo sobre la política de agresión"76.

Cabe destacar que el control efectivo sobre las instituciones del Estado agresor no siempre ha sido exigido para predicar responsabilidad penal por el crimen de agresión. Así, por ejemplo, el Tribunal Militar Internacional para el Lejano Oriente (TMILO) condenó a varios líderes japoneses aun cuando no participaron realmente en la planeación, iniciación o ejecución de una guerra de agresión; a pesar de que tal condición estaba prevista en el artículo 5 (c) del Estatuto de dicho Tribunal. En particular, el Tribunal consideró que el único eximente de responsabilidad válido habría sido el retiro efectivo de la posición como dirigente político o militar. Como puede apreciarse, el TMILO determinó que el hecho de ostentar una posición de dirección en el Estado agresor comprometía automáticamente la responsabilidad penal por el inicio y desarrollo de la guerra de agresión; tesis que encuentra fundamento en el concepto de conspiracy del derecho anglosajón y que puede considerarse como un primer antecedente de la doctrina de la joint criminal enterprise $e^{77}$.

Ahora bien, en lo que hace a las consecuencias de admitir el carácter del crimen de agresión como crimen de dirigentes, debemos apartarnos de lo considerado por CoRREDOR en el sentido de que tal hecho comporta una contradicción con las conductas consagradas como verbos rectores de este delito de derecho internacional. En particular, el citado autor censura que se establezca como supuesto de responsabilidad la

75 Aмвоs. El crimen de agresión después de Kampala, cit., p. 45.

76 Aмвоs. El crimen de agresión después de Kampala, cit., p. 47.

77 Cfr. NeIL Boister. "The Application of Collective and Comprehensive Criminal Responsibility for Agression at the Tokyo International Military Tribunal”. Journal of International Criminal Justice, vol. 8, 2010 . 
realización de un acto de agresión, pues tal conducta, en su criterio, no es desarrollada por los dirigentes sino por sus subordinados ${ }^{78}$. En nuestro concepto la crítica de CORREDOR obedece a una comprensión excesivamente ontológica del concepto de realización, la cual se aproxima a una concepción objetivo formal del fenómeno delictivo. Al respecto, cabe recordar que en tratándose de conductas encauzadas a través de organizaciones jerárquicamente organizadas dotadas de una estructura más o menos compleja, la realización es predicable tanto de quien de propia mano ejecuta la conducta como de quien ha delineado la política de dicha organización que se traduce en la acción delictiva ${ }^{79}$. En otras palabras, el dirigente de un Estado realiza el acto de agresión a través de la organización estatal, a pesar de hallarse a cientos de kilómetros de distancia del lugar en que tiene lugar el acto de agresión.

El reconocimiento del crimen de agresión como crimen de dirigentes lleva aparejada la discusión acerca de la responsabilidad de quienes, sin ostentar posiciones de mando, participan en la planeación o ejecución de un acto de agresión. En relación con la responsabilidad penal de los extraneus por la comisión del crimen de agresión, es decir, de quienes no tienen el poder de control o dirección antes señalado, la resolución adoptada en Kampala introdujo un nuevo parágrafo al artículo 25 del ECPI, relativo a las formas de autoría y participación, en el que expresamente se indica que "Por lo que respecta al crimen de agresión, las disposiciones del presente artículo sólo se aplicaran a las personas en condiciones de controlar o dirigir efectivamente la acción política o militar de un Estado". Como puede advertirse, la mentada disposición impide que los extraneus puedan ser considerados partícipes del crimen de agresión, a pesar de que, por regla general, tales formas de intervención en el delito - complicidad y determinación- no exigen la concurrencia de las calidades especiales exigidas por el autor. Lo anterior, en nuestro concepto, no quiere decir que frente al crimen de agresión no se prediquen las formas de participación consagradas en los literales b), c) y d) del parágrafo 3. . del artículo 25, pues bien puede ocurrir que un alto funcionario del Estado, pese a tener dominio efectivo sobre las fuerzas políticas, participe de forma secundaria en la elaboración o ejecución de un acto de agresión grave de los indicados en el artículo 8 bis; caso en el cual deberá ser considerado cómplice al contar con la calidad exigida por el artículo, pero carecer de dominio del hecho ${ }^{80}$. La postura aquí defendida también es sostenida por KREß y HOLTZENDORFF, para quienes la definición del crimen de agresión alcanzada en Kampala adopta un

78 Cfr. Corredor CARvajal, ob. cit., p. 68. En relación con este punto señala: “a la vez y sin distinción se hace referencia a la persona que dirige o controla y al individuo que planifica, prepara, inicia o realiza un acto de agresión como elementos de comportamiento que no se excluyen entre sí, a pesar de que haya sido lógicamente establecido".

79 Díaz Soto. La responsabilidad del dirigente de organizaciones criminales estructuradas jerárquicamente. Tesis de maestría. 2011.

80 CORREDOR se aparta de la tesis aquí defendida, al sostener que "en resumen tratándose del crimen de agresión, la definición dejó sin efectos jurídicos la distinción entre autores y partícipes". CORREDOR CARVAJAL, ob. cit., p. 82. 
enfoque diferencial en materia de responsabilidad penal, de modo que el grado de responsabilidad en cada caso deberá determinarse conforme a las distintas modalidades de autoría y participación previstas en la señalada disposición ${ }^{81}$.

Cabe destacar que el mencionado artículo 25 fue la única disposición de la parte general del derecho penal internacional que fue modificada para adecuarla a las particularidades del crimen de agresión, lo que resulta comprensible pues ningún sentido tendría la consagración del crimen de agresión como crimen de dirigentes y, simultáneamente, que se extendiera la responsabilidad por este crimen a los funcionarios de base por vía del instituto de la complicidad.

\section{EL ELEMENTO SUBJETIVO DEL CRIMEN DE AGRESIÓN}

La doctrina más respetada coincide en señalar que el tipo subjetivo o mens rea de los crímenes internacionales, previsto en el artículo 30 del ECPI, solo puede comprenderse adecuadamente en referencia a los elementos materiales de dichas conductas o actus $r e a^{82}$. Es decir, el Estatuto dispone un determinado nivel de conocimiento y actitud frente a cada uno de los elementos que integran el tipo objetivo de los crímenes internacionales. En efecto el mentado artículo 30 describe una estructura de los crímenes internacionales comprendida por conducta, consecuencias y circunstancias. Respecto de la conducta, esto es, de la acción individual, se demanda la intención de incurrir en ella, lo que supone conocimiento y voluntad, esto es, la conducta individual debe ser ejecutada con dolo genérico ${ }^{83}$. En cuanto a la consecuencia o resultado de la conducta, el Estatuto prevé dos formas de mental element o tipo subjetivo: i) el propósito de conseguir el resultado típico, o ii) la consciencia de que la consecuencia se producirá en el curso normal de los acontecimientos; esta última referencia se asemeja al llamado dolo indirecto o de segundo grado, no así al dolo eventual pues, como bien lo señala AmBos, "con esto [art. 30(2)(b)] se exige más que el dolus eventualis, pues allí el tener seriamente por posible la producción del resultado se funda en una base fáctica insegura, mientras que aquí se puede partir de un modo relativamente seguro de la producción del resultado" 84 . Por último, frente a las circunstancias, esto es, en relación con el elemento de contexto que dota las conductas individuales de su relevancia internacional, la norma en comento exige la consciencia (awareness) de que existen, es decir, las circunstancias en que se desarrolla la conducta individual que la caracterizan como crimen internacional deben ser advertidas por el autor, lo que no exige un conocimiento detallado del plan criminal o de las características de dichas circunstancias ${ }^{85}$.

81 KREß Y HOLTZENDORFF, ob. cit., p. 1189.

82 Cfr. Ambos. La Parte General del Derecho Penal Internacional, cit. WerLe. ob cit.

83 Ambos. La Parte General del Derecho Penal Internacional, cit., p. 396.

84 Ibíd., p. 898.

85 Ibíd., p. 404. 
Si bien el artículo 30 del ECPI no sufrió modificaciones en razón a la consagración del crimen de agresión, es necesario reflexionar acerca del modo en que las exigencias subjetivas previstas en la señalada norma se predicarán de cada uno de los elementos del crimen, en particular en relación con la pluralidad de elementos de contenido normativo que lo componen. En efecto, conceptos como "acto de agresión", "soberanía", "integridad territorial", "independencia política", "violación manifiesta de la CNU", etc. están dotados de un fuerte contenido normativo y político. Así entonces debemos preguntarnos: ¿es necesario que el sujeto agente del acto de agresión tenga consciencia de que su conducta constituye una violación manifiesta del derecho internacional o, más aún, desee infringir los mandatos del derecho internacional público?; de no concurrir este conocimiento o deseo, ¿puede en todo caso predicarse responsabilidad por este crimen internacional?

En lo que hace al elemento subjetivo frente a los componentes normativos de los crímenes internacionales, AмBоs sostiene que el dolo se predica de estos elementos con base en la teoría de la valoración paralela -"valoración paralela en la esfera de lo profano"- conforme a la cual si el sujeto es consciente de los elementos fácticos que integran el concepto normativo, se entiende que lo ha reconocido, es decir, el dolo frente a los elementos normativos del tipo objetivo no se constata, sino que se imputa o atribuye. En tal sentido señala AmBos en relación con el elemento normativo circunstancial "conflicto armado" propio de los crímenes de guerra:

... si se concibe el requisito del conflicto armado como un elemento del tipo abarcado por el dolo, entonces para la teoría de la valoración paralela sería necesario, pero también suficiente, que el autor tuviera conocimiento de las hostilidades o enfrentamientos que tienen lugar y que con base en ello haya podido reconocer la existencia de un conflicto armado. El conocimiento del componente normativo del elemento del tipo es supuesto por tanto con base en un determinado conocimiento factual. Esta atribución ficticia encuentra un punto de apoyo en el Derecho Penal Internacional, puesto que precisamente el autor no tiene que realizar una valoración jurídica, sino que ya actúa con dolo, si él tiene un mero conocimiento factual. In concreto, es suficiente con que el autor reconozca la existencia ficticia de un conflicto $\operatorname{armado}^{86}$.

Lo señalado respecto del crimen de guerra es perfectamente predicable del crimen internacional de agresión. Es decir, el único conocimiento efectivo que se exige al autor de esta conducta es el relacionado con su posición de mando y con el uso de la fuerza armada que planea, prepara o ejecuta, de modo que a partir de estos elementos se desprende la conciencia (awareness) de la ilicitud de la acción armada desplegada por el Estado que dirige.

86 Ibíd., p. 215. 
Lo anterior, lejos de ser una interpretación caprichosa, se compadece por entero con los Elementos de los Crímenes ${ }^{87}$ atinentes al crimen de agresión. En efecto, los numerales de $2 .^{\circ}$ y $4 .^{\circ}$ de la introducción del artículo 8 bis de los Elementos preceptúan: "No existe obligación de demostrar que el autor haya llevado a cabo una evaluación en derecho de la incompatibilidad del uso de la fuerza armada con la Carta de las Naciones Unidas", y "No existe la obligación de demostrar que el autor haya llevado a cabo una evaluación en derecho de la naturaleza 'manifiesta' de la violación de la Carta de las Naciones Unidas". De igual modo, los elementos 4..$^{\circ}$ y 6 . $^{\circ}$ del crimen de agresión, previstos también en el señalado artículo 8 bis, establecen como requisitos para que se entienda estructurada esta conducta "Que el autor haya tenido conocimiento de las circunstancias de hecho que determinaban la incompatibilidad de dicho uso de la fuerza armada con la Carta de las Naciones Unidas"; e igualmente el numeral 6 de los Elementos establece: "que el autor haya tenido conocimiento de las circunstancias de hecho que constituían dicha violación manifiesta de la Carta de las Naciones Unidas".

Como se observa, la CPI debe verificar que el autor sea consciente de las circunstancias fácticas que dan lugar a que el uso de la fuerza armada sea incompatible con la CNU, pero es innecesaria la demostración de que el sujeto agente evaluó jurídicamente su conducta o de los resultados de dicha evaluación. En otras palabras, una vez la Corte verifique que el acto de agresión constituyó una violación manifiesta de la CNU, la consciencia del autor sobre tal punto de derecho resultará intrascendente para efectos de estructurar su responsabilidad ${ }^{88}$.

Este criterio es también sostenido por AmBos, quien en relación con los supuestos de error que podrían configurarse frente al crimen de agresión y su trascendencia, sostiene:

... a diferencia de lo que ocurre con los otros crímenes del Estatuto, esta consciencia no equivale a una comprensión jurídica, esto es, al conocimiento de los elementos legales que convierten a un determinado uso de la fuerza en un acto estatal ilícito o incluso en un crimen de agresión. Esta consciencia presupone un conocimiento efectivo, no un estándar menor como el conocimiento constructivo o incluso el recklessness. [...] La preferencia por el "conocimiento de los hechos" por sobre el "conocimiento de la ley" conduce a que, en principio, sólo un error de hecho (artículo 32 (1) del ECPI) sea relevante, mientras que un error de derecho (artículo 32 (2)) estaría precluido in limine,

87 Corte Penal Internacional. Elementos de los Crímenes, U.N. Doc. PCNICC/2000/1/Add.2 (2000).

88 En contra Leclerc-Gagné y M.Byers, citados por O’CONNELl y NiYAZMATOv, ob. cit., p. 206, para quienes la motivación que dio lugar al uso de la fuerza también puede ser vista como una defensa para el "acusado", por ejemplo en los casos de intervención humanitaria. 
a menos que haga desaparecer el elemento de intencionalidad requerido por ese crimen (artículo 32 (2) segunda oración) ${ }^{89}$.

En conclusión, las exigencias subjetivas del crimen de agresión se limitan a un conocimiento efectivo de la posición de mando y del uso de la fuerza armada por el Estado agresor, resultando innecesario demostrar que se tenía consciencia o deseo de incurrir en una violación manifiesta de los mandatos del derecho internacional público.

\section{LA TENTATIVA DEL CRIMEN INTERNACIONAL DE AGRESIÓN}

Escapa por mucho al objeto del presente artículo adelantar una exposición detallada del instituto de la tentativa, que en el ámbito del derecho penal internacional adquiere nuevas complejidades. No obstante, resulta necesario detenerse brevemente en las características de la tentativa a la luz de su consagración en el ECPI, como antesala de su análisis frente al crimen internacional de agresión.

La doctrina consultada coincide en afirmar que la institución de la tentativa ha desempeñado un escaso papel en el derecho penal internacional, en particular, no existen decisiones judiciales en la que se haya enjuiciado la tentativa de comisión de crímenes de derecho internacional. No obstante, también se reconoce de forma unánime ${ }^{90}$ que desde sus inicios el derecho internacional penal ha reconocido la punibilidad de actos previos a la ejecución del crimen propiamente dicho; tal es el caso de la intervención en un plan común o conspiración para cometer un crimen contra la paz, conducta prevista como supuesto típico de esta categoría de crímenes internacionales. De forma expresa la tentativa fue codificada por primera vez en el ámbito del derecho penal internacional en el artículo III (d) de la Convención contra el Genocidio. Lo señalado en dicha Convención y en las distintas propuestas de codificación del derecho internacional penal permite concluir que en el ámbito de esta área del derecho se reconoce la punibilidad de la tentativa, bien sea que la misma se funde en la costumbre internacional o en los principios generales del derecho ${ }^{91}$.

Ahora bien, en el ECPI la tentativa fue consagrada en el literal f) del numeral 3. ${ }^{\circ}$ del artículo 25, conforme al cual: "será penalmente responsable por un crimen de competencia de la Corte quien intente cometer ese crimen mediante actos que supongan un paso importante para su ejecución, aunque el crimen no se consume debido a circunstancias ajenas a su voluntad. Sin embargo, quien desista de la comisión del crimen o impida que de otra forma se consuma [sic] no podrá ser penado de conformidad con el presente estatuto si renunciare integra y voluntariamente al propósito delictivo".

89 Амвоs. El crimen de agresión después de Kampala, cit., p. 54.

90 Cuando menos en lo que respecta a la doctrina consultada.

91 Амвоs. La Parte General del Derecho Penal Internacional, cit., p. 336. 
La fórmula bajo la cual se consagró la responsabilidad penal por tentativa en el ECPI supone una opción ecléctica que combina posiciones aparentemente contrapuestas; a saber: la solución francesa, conforme a la cual la tentativa requiere que principie la ejecución de la conducta típica, y la propuesta norteamericana, fundada en la teoría del "substantial step", que no necesariamente debe desarrollarse en la fase ejecutiva del iter criminis $^{92}$.

En todo caso, debe quedar claro que la referencia a acciones que "supongan un paso importante para su ejecución” no implica la realización del tipo penal, es decir, en el escenario del derecho penal internacional no tiene cabida la teoría objetivo formal en lo referente a la tentativa. En tal sentido Aмвоs afirma:

... la versión castellana del art. 25(3)(f) oración 1 se refiere a acciones que “supongan un paso importante para su ejecución”. En ambos casos no se exige por tanto la realización parcial del tipo, sino solamente una acción que represente un paso importante hacia la realización del delito; con esto, quedan comprendidas también las acciones que ocurren con anterioridad a la propia realización del tipo ${ }^{93}$.

La referencia al substancial step resalta el elemento objetivo de la tentativa en el plano del derecho internacional penal; lo que no quiere decir que pueda hacerse caso omiso a la intención del autor a la hora de determinar si tal substancial step ha tenido o no ocurrencia. No obstante, lo que sí queda claro es que "no es suficiente con que el autor se sienta subjetivamente fortalecido con el 'substancial step', sino que, más bien, este paso debe representar también un acercamiento objetivo a la meta perseguida. La tentativa es, de acuerdo con esto, la voluntad criminal del autor manifestada objetivamente" 94 .

Por su parte, la figura del desistimiento de la tentativa ha sido recogida de forma negativa y positiva en el ECPI. Negativa: al disponerse que la responsabilidad penal por tentativa exige que el resultado típico no se alcance por circunstancias ajenas a la voluntad del agente. Positiva: Al consagrarse expresamente la institución del desistimiento, en los siguientes términos: "quien desista de la comisión del crimen o impida de otra forma que se consuma no podrá ser penado de conformidad con el presente estatuto por la tentativa si renunciare integra y voluntariamente al propósito delictivo". La primera oración del artículo 25(3)(f) permite concluir que el desistimiento excluye la responsabilidad penal por tentativa, esto es, se trata de una plena "defence" y no de una mera atenuación de responsabilidad. Como bien lo señala AmBos: "el

92 Ibíd., p. 336.

93 Ibíd., p. 348.

94 Ibíd., p. 349. 
desistimiento voluntario se transforma en un elemento negativo del tipo de la definición de la tentativa y su falta en un presupuesto implícito del tipo de tentativa" 95 .

Ahora bien, decantados los rasgos básicos de la responsabilidad por tentativa bajo el ECPI, es necesario valorar de qué modo los preceptuados en el artículo 25(3)(f) pueden tener aplicación frente al crimen internacional de agresión. Al respecto, desde ya debe señalarse que la Conferencia de Revisión, al introducir el artículo 8 bis a los Elementos de los Crímenes, restringió severamente la posibilidad de tentativa del crimen de agresión. En efecto, como tercer elemento del mencionado crimen internacional se señala: "que el acto de agresión -el uso de la fuerza armada por un Estado contra la soberanía, la integridad territorial o la independencia política de otro Estado, o en cualquier otra forma incompatible con la Carta de las Naciones Unidas- se haya cometido". Como puede observarse, los elementos del crimen de agresión expresamente impiden que la mera ideación o preparación del crimen de agresión dé lugar a responsabilidad penal, aun cuando constituya un substancial step.

Podría pensarse que la responsabilidad por tentativa tendría cabida en aquellos supuestos en que el uso de la fuerza armada no alcanza -por sus características, gravedad y escala- a constituir un acto de agresión manifiestamente contrario a la CNU; sin embargo, debe recordarse, como se señaló anteriormente, que el artículo 8 bis no consagra dos categorías de agresión, sino simplemente reafirma que el uso de la fuerza armada, para ser considerado un acto de agresión, debe reunir determinadas condiciones de gravedad y escala que lo tornen manifiestamente contrario a la CNU. En otras palabras, los usos ilícitos de la fuerza armada por parte de un Estado que no reúnan las condiciones antes anotadas, no son substancial steps de un acto de agresión, sino ilícitos internacionales que, precisamente por no constituir un acto de agresión, carecen de entidad para comprometer la responsabilidad penal internacional de sus autores; cuando menos por el crimen de agresión.

Así entonces, el único supuesto en que se estructuraría la tentativa del crimen de agresión sería aquel en que se ha dado inicio a un auténtico acto de agresión, pero el mismo no logra alcanzar toda su potencialidad en razón a circunstancias ajenas al Estado agresor. Piénsese en un Estado que ha movilizado un gran número de unidades militares con el expreso propósito de anexar por la fuerza un territorio del Estado vecino, pero una vez iniciados los enfrentamientos, sin que estos por su gravedad y escala alcancen la condición de acto de agresión, se ve obligado a ordenar la retirada de sus tropas por la acción eficaz de los Consejo de Seguridad de las NU.

95 Ibíd., p. 339. 


\section{LOS MECANISMOS DE ACTIVACIÓN DE LA JURISDICCIÓN DE LA CPI SOBRE EL CRIMEN DE AGRESIÓN}

La reforma al ECPI aprobada en Kampala supone una modificación sustancial al régimen jurisdiccional de la Corte. Conforme lo dispone el artículo 12 del Estatuto, la Corte tendrá competencia para conocer de aquellos crímenes cometidos en el territorio de un Estado parte, lo que unánimemente ha sido entendido como el reconocimiento de la posibilidad de que nacionales de Estados no parte puedan ser enjuiciados por la Corte por la comisión de crímenes internacionales en el territorio de un Estado que ha aceptado la jurisdicción del Tribunal ${ }^{96}$. Sin embargo, el artículo 15 bis, que consagra un régimen especial para el ejercicio de la competencia por el crimen de agresión, expresamente establece que "5. Respecto de un Estado no Parte en el presente Estatuto, la Corte no ejercerá su competencia respecto del crimen de agresión cuando este sea cometido por los nacionales de ese Estado o en el territorio del mismo". Como puede observarse, la reforma expresamente excluye la competencia de la Corte frente a aquellos actos de agresión ejecutados por Estados no parte e independientemente de que se dirijan contra Estados que sí han ratificado el Estatuto; lo anterior salvo que la situación sea remitida directamente por el Consejo de Seguridad de las NU bajo los parámetros del artículo 15 ter, caso en el cual la Corte podrá ejercer su competencia respecto de los nacionales de cualquier Estado, con independencia de que se haya adherido o no al Estatuto de Roma, o haya presentado reservas frente a la jurisdicción de la Corte sobre el crimen de agresión.

En lo que hace a las condiciones para el ejercicio de la competencia de la Corte sobre el crimen de agresión, es necesario distinguir dos escenarios:

\section{Remisión de la situación por un Estado parte o inicio de la investigación a iniciativa de la Fiscalía}

Si la situación en la que podría haberse configurado un crimen de agresión ha sido remitida por un Estado parte o el Fiscal considera, motu proprio, que existe fundamento razonable para iniciar una investigación por este crimen, deberá verificar si el Consejo de Seguridad ha declarado la existencia de un acto de agresión; de no ser así, el Fiscal notificará al Secretario General de las NU para que el Consejo de Seguridad, en un plazo máximo de seis (6) meses, proceda a determinar si concurre

96 Al respecto, PoLITI destaca que el artículo 12 del ECPI habilita a la Corte a ejercer su jurisdicción sobre nacionales de Estados no Parte, siendo precisamente esta disposición la que motivó al gobierno de Estados Unidos a suscribir múltiples acuerdos bilaterales con los Estados Parte del ECPI para excluir a sus ciudadanos de la competencia de la Corte, bajo el artículo 98(2). El autor destaca que el principio consagrado en el artículo 12 se ve desvirtuado por las condiciones establecidas para el ejercicio de la jurisdicción sobre el crimen de agresión, pues solo el reconocimiento expreso por el Estado agresor no Parte activaría la competencia de la Corte. MAUro Politi. "The ICC and the crime of aggression. A dream that came though and the reality ahead". Journal of International Law, vol. 10, 2012, p. 277. 
o no un acto de agresión. En el evento de que transcurrido dicho término el Consejo no se haya pronunciado, el Fiscal podrá iniciar la investigación previa autorización de la Sección, que no de la Sala de Cuestiones Preliminares ${ }^{97}$.

Este procedimiento puede interpretarse como una reivindicación de la autonomía de la CPI frente al Consejo de Seguridad, pues si bien la Resolución 3314 expresamente establece que la existencia de un acto de agresión debe ser declarada por dicho órgano, el Estatuto permite que se dé inicio a una investigación por el crimen objeto de investigación incluso en ausencia de tal declaratoria.

La resolución guarda silencio acerca de los efectos de una declaración negativa por parte del Consejo de Seguridad, esto es, de una decisión de dicho órgano en el sentido de que no se ha configurado un acto de agresión. Algún sector de la doctrina ha identificado tal omisión como el reconocimiento tácito de la posibilidad de que el Fiscal solicite a la Sección de Cuestiones Preliminares autorización para el inicio de una investigación por la probable comisión de un crimen de agresión, aun mediando una determinación negativa del Consejo de Seguridad acerca de la ocurrencia del acto de agresión ${ }^{98}$.

Como fundamento de tal postura se acude a una interpretación extensiva de los numerales $9 .^{\circ}$ y $4 .^{\circ}$ de los artículos 15 bis y 15 ter, respectivamente; en particular, se considera que si la determinación de que hubo un acto de agresión realizada por un órgano ajeno a la Corte no condiciona las conclusiones a las que esta arribe en cuanto a la responsabilidad de los acusados, tampoco la negativa a declarar tal acto subordina el criterio de la Corte en relación con la efectiva ocurrencia de un crimen de agresión ${ }^{99}$.

Así mismo, se señala que el numeral 7. ${ }^{\circ}$ del artículo 15 bis no condiciona el sentido de la "determinación” del Consejo de Seguridad, de modo que cualquiera sea la decisión de dicho organismo, podría iniciar una investigación por la probable comisión de un crimen de agresión. Bajo esta hermenéutica, los efectos de la decisión negativa del Consejo de Seguridad respecto a la ocurrencia de un acto de agresión serían los mismos que los que se derivan del silencio de dicho órgano, esto es, la necesidad de obtener autorización de la Sección de Cuestiones Preliminares para iniciar la investigación.

Debemos apartarnos de esta interpretación de la enmienda, pues omite considerar que el artículo 5. ${ }^{\circ}$ del Estatuto de la CPI, en su redacción original, expresamente señalaba que las disposiciones que se adoptaran en relación con la definición del crimen de

97 Art. 15 bis. del ECPI.

98 Cfr. Corredor Carvajal, ob. cit., p. 192 ss. Politi. "The ICC and the Crime of Aggression", cit., p. 273.

99 Cfr. Corredor Carvajal, ob. cit., p. 198. 
agresión y las condiciones para el ejercicio de la competencia de la Corte sobre el mismo, debían ser "compatibles" con la CNU; instrumento que sin dubitación alguna confiere al Consejo de Seguridad la competencia de declarar la existencia de un acto de agresión y desplegar el mecanismo de seguridad colectiva previsto en el título VII de la CNU.

Precisamente, fue la existencia de este mandato de desarrollo del crimen de agresión en concordancia con la CNU, lo que suscitó los mayores interrogantes por parte de la doctrina que se ocupó de la reglamentación del crimen de agresión en el Estatuto de la CPI antes de la adopción de la Resolución RC/RES. 6; autores que con acertado criterio anticiparon que el reto de la enmienda al Estatuto vendría dado por reconocer la competencia del Consejo de Seguridad frente al acto de agresión, sin menoscabar la independencia de la Corte $^{100}$.

En consecuencia, no puede optarse por una interpretación del texto de la enmienda que ignore las competencias otorgadas por la CNU al Consejo de Seguridad; independientemente de las críticas ${ }^{101}$, muchas de las cuales son válidas, que suscita el manejo político al interior del Consejo de Seguridad y a la ineptitud que ha mostrado en el pasado para afrontar situaciones que comprometen la paz y seguridad internacional.

De aceptarse la hermenéutica propuesta por los autores citados, debería igualmente concluirse que los redactores de la enmienda establecieron un procedimiento de consulta ante el Consejo de Seguridad carente de cualquier efecto jurídico en lo que hace a la determinación de la ocurrencia de un crimen de agresión, de modo que lo decidido por dicho órgano solo tendría trascendencia en lo que hace al procedimiento a seguir para iniciar la investigación por tal delito; interpretación que al menos en teoría conduciría a una autonomía absoluta de la Corte frente a lo determinado por el Consejo de Seguridad.

Como puede advertirse, la postura doctrinal aquí debatida parte de un supuesto errado, esto es, que la CPI tiene plena autonomía frente a las determinaciones del Consejo de Seguridad; lo cual, aunque deseable, no se compadece con el texto del Estatuto ni de su enmienda ${ }^{102}$. Por el contrario, en tratándose del crimen de agresión, los re-

100 Ver, entre otros, WERLE, ob. cit., p. 765 ss. SUNGA, ob. cit., p. 242.

101 Muchas organizaciones de derechos humanos han publicado reportes y recomendaciones dando a conocer su oposición frente al establecimiento de un filtro jurisdiccional externo como el CSNU o la AGNU, considerando que esto podría politizar la decisión respecto a la existencia de un acto de agresión, afectando de esta forma la independencia e imparcialidad de la CPI. Al respecto ver LEONIE vON BRAun y AnNelen Micus. "Judicial independence at risk". Journal of International Criminal Justice, vol. 10, Oxford University Press, 2012, p. 120.

102 Para tal efecto, ver ibíd., p. 126, para quienes el preámbulo del ECPI aboga por una corte penal internacional independiente respecto al Sistema de las Naciones Unidas, y además sostienen que el Estatuto le otorga plenos poderes para investigar al Fiscal; por el contrario, el cSNU o un Estado solo 
dactores del Estatuto expresamente establecieron que la definición y condiciones de competencia sobre dicho delito debían responder a la CNU y, por ende, respetar el rol asignado al Consejo de Seguridad en cuanto órgano llamado a declarar la ocurrencia de un acto de agresión.

Adicionalmente, resulta difícil conciliar la escasa entidad que pretende atribuírsele a la negativa del Consejo de Seguridad a declarar la existencia de un acto de agresión, con otras disposiciones del Estatuto que otorgan una amplia influencia a dicho órgano sobre el desarrollo de las labores de la CPI, en particular, con el artículo 16 que faculta al Consejo de Seguridad para, conforme a las condiciones allí señaladas, solicitar a la Corte la suspensión de una investigación o juzgamiento; petición que deberá ser atendida por la Corte.

Si el Consejo de Seguridad goza de tan amplias facultades respecto a la investigación y juzgamiento de crímenes sobre los cuales carece de cualquier influencia en la valoración de su efectivo acaecimiento, con mayor razón deben reconocérsele efectos jurídicos a la decisión de negar la existencia del elemento esencial del crimen de agresión, es decir, el acto de agresión; pues es a dicho órgano al que la CNU le ha asignado la competencia para determinar su efectiva ocurrencia.

Contra lo aquí planteado nada dice el texto de los numerales $4 .^{\circ}$ y $9 .^{\circ}$ de los artículos 15 bis y 15 ter, respectivamente, conforme al cual "la determinación de que hubo [un] acto de agresión realizada por un órgano ajeno a la Corte no irá en perjuicio de las propias conclusiones de la Corte en virtud del presente estatuto". En primer lugar, porque las disposiciones citadas expresamente se refieren al evento en que el Consejo de Seguridad ha declarado la existencia de un acto de agresión, no así cuando la ha negado. En segundo término, y más relevante aún, porque la norma transcrita es desarrollo de la definición del crimen de agresión consagrada en el artículo 8 bis, conforme a la cual la configuración de un acto de agresión resulta insuficiente para predicar la responsabilidad penal de los dirigentes del Estado agresor. En otras palabras, la normatividad transcrita pretende reafirmar que la existencia de un acto de agresión no basta para considerar a los procesados responsables de un crimen de agresión y que tal determinación, esto es, la concerniente a la responsabilidad penal de los enjuiciados, es de competencia exclusiva de la Corte.

Adicionalmente, no resulta convincente el argumento esbozado por CORREDOR según el cual el numeral 7. ${ }^{\circ}$ del artículo 15 bis no establece cuál debe ser el sentido de la determinación del Consejo de Seguridad, de modo que la investigación podrá iniciarse

pueden señalar una situación en que parezca haberse cometido uno o varios crímenes (art. 13 a y b ECPI). El artículo 16 del ECPI es visto como una interferencia en la independencia de la Corte, razón por la cual organizaciones como Amnistía Internacional y Human Rights Watch han dicho que el mencionado artículo debe tener una interpretación restrictiva. 
una vez se constate que dicha determinación fue adoptada independientemente de su sentido ${ }^{103}$. Frente a este argumento, baste con señalar que el mentado numeral $7 .^{\circ}$ no puede interpretarse con independencia de lo preceptuado en el numeral $6 .^{\circ}$ del mismo artículo, del que claramente se desprende que la determinación del Consejo de Seguridad sobre la ocurrencia del acto de agresión debe haber sido adoptada en sentido positivo, de tal forma que solo en ese evento el Fiscal podrá iniciar una investigación por el crimen bajo análisis sin que medie la autorización de la Sección de Cuestiones Preliminares. De aceptarse la interpretación postulada por el citado autor, se llegaría a la conclusión que el Fiscal puede iniciar motu proprio una investigación por el crimen de agresión cuando el Consejo de Seguridad confirme o niegue la existencia de un acto de agresión, en tanto que cuando dicho órgano guarde silencio deberá la Fiscalía contar con autorización previa de la Sección de Cuestiones Preliminares; conclusión que carece de cualquier coherencia.

En conclusión, en nuestro criterio la declaratoria de inexistencia de un acto de agresión por parte del Consejo de Seguridad impediría al Fiscal iniciar una investigación por un crimen de agresión y, en consecuencia, a la Corte adelantar su enjuiciamiento.

Por otra parte, conviene detenerse en el procedimiento previsto en caso de que el Consejo de Seguridad se sustraiga de la declaratoria a la que se viene haciendo referencia. Si transcurridos seis (6) meses desde la remisión de la situación a la ONU no se ha proferido el pronunciamiento reclamado por el Fiscal, este podrá acudir a la Sección de Cuestiones Preliminares para que se le autorice a iniciar la investigación por un crimen de agresión. Nótese que esta labor no fue confiada a la Sala de Cuestiones Preliminares, como ocurre en relación con los restantes crímenes internacionales de competencia de la Corte, sino a la Sección en pleno; medida que se explica en razón a las consecuencias internacionales que tiene el reconocimiento -incluso tácito- de un acto de agresión ${ }^{104}$. Esta disposición, si bien justificada con miras a establecer un filtro más riguroso ante la ausencia de un pronunciamiento expreso por parte del Consejo de Seguridad, genera nuevos interrogantes en relación con la labor de la Sección de Cuestiones Preliminares como órgano jurisdiccional. Como bien lo anota POLITI, hasta antes de la conferencia de revisión el ECPI no confería facultades jurisdiccionales a la Sección, lo que demanda la adopción de un reglamento en el que se precise el modo en que este órgano desarrollará su tarea (bajo qué mayoría deben adoptarse las decisiones, cómo se resolverán las paridades ante la toma de una decisión, de qué modo se distribuirán las funciones al interior de la Sección, etc.) ${ }^{105}$.

Más importante aún, conviene que se aclare cuáles serán los criterios que tendrá en consideración la Sección para autorizar el inicio de una investigación por el crimen

103 Corredor Carvajal, ob. cit., p. 196.

104 PoLiti. "The ICC and the Crime of Aggression", cit., p. 275

105 Ibíd., p. 275. 
de agresión. Conforme a la doctrina sentada por la Sala de Cuestiones Preliminares II, para la autorización de inicio de una investigación se requiere un estándar probatorio inferior al que demanda el proferimiento de una orden de arresto; además, dicha exigencia probatoria se satisface con evidencia no necesariamente conclusiva o irrebatible de la comisión de un crimen de competencia de la Corte ${ }^{106}$. Dada la trascendencia política que tendría el inicio de una investigación por el crimen de agresión, más aún en ausencia de la declaratoria de un acto de agresión por el Consejo de Seguridad, convendría que se fijaran, para autorizar el inicio de una investigación por este crimen, criterios más rigurosos que los actualmente imperantes frente a los restantes delitos de competencia de la Corte.

\section{Remisión de la situación por el Consejo de Seguridad}

El artículo 15 ter regula lo concerniente al ejercicio de la competencia de la Corte frente al crimen de agresión cuando la situación ha sido remitida por el propio Consejo de Seguridad de las NU. En este supuesto conviene reiterar que la competencia de la Corte no estará supedita a la nacionalidad de sus autores o la exigencia de un vínculo territorial con los hechos, es decir, la remisión del Consejo de Seguridad habilita a la Corte para investigar, enjuiciar y sancionar a los responsables del crimen de agresión independientemente de que el Estado agresor haga parte del Estatuto o haya ratificado la enmienda.

Infortunadamente la enmienda no establece cuáles son los efectos en el plano procesal de dicha remisión, en particular, si aún en este evento el Fiscal debe solicitar autorización a la Sección de Cuestiones Preliminares para el inicio de una investigación por el crimen de agresión. Al respecto, consideramos que en este caso debe procederse del mismo modo previsto en el numeral 7. ${ }^{\circ}$ del artículo 15 bis, es decir, del mismo modo que en aquellos casos en que el Consejo de Seguridad, a petición de la Fiscalía, ha declarado la existencia de un acto de agresión, evento en el que el inicio de la investigación no estará supeditado a la autorización de la Sección o de las Salas de Cuestiones Preliminares. Esta misma tesis es sostenida por PoLITI, para quien razones de economía procesal llevan a concluir que en estos casos es posible prescindir de la autorización de la Sección de Cuestiones Preliminares para dar inicio a una investigación por el crimen de agresión ${ }^{107}$.

106 Sala de Cuestiones Preliminares II, Decisión conforme al artículo 15 del ECPI de autorización para el inicio de una investigación frente a la situación en la República de Kenya, 31 de marzo de 2010 (ICC01/09-19). Más recientemente: Sala de Cuestiones Preliminares II, Decisión conforme al artículo 15 del ECPI de autorización para el inicio de una investigación frente a la situación de la República de Costa de Marfil, 3 de octubre de 2011 (ICC/02/11-14).

107 PoLiti. "The ICC and the Crime of Aggression", cit., p. 273. 


\section{LAS CONDICIONES PARA LA ENTRADA EN VIGOR DE LA ENMIENDA}

La entrada en vigor de las enmiendas al ECPI relativas al crimen de agresión, en particular, las relacionadas con los mecanismos de activación de la jurisdicción de la Corte sobre este crimen, está sujeta a dos condiciones, a saber: 1) que treinta (30) Estados Parte ratifiquen o acepten la enmienda ${ }^{108}$-art. 15 bis (2) y 15 ter (2)-, y 2) que se adopte una decisión después del 1. ${ }^{\circ}$ de enero de 2017 por la misma mayoría de los Estados Parte que se requiere para la aprobación de la enmienda al Estatuto -art. 15 bis (3) y 15 ter (3)-.

Al respecto, lo primero que habría que aclarar es que estas condiciones de entrada en vigor son predicables de todos los mecanismos de activación de la jurisdicción de la Corte previstos en el artículo 13 del ECPI; es decir, bien sea que la situación sea remitida por el Consejo de Seguridad, por un Estado Parte o que el Fiscal adelante una investigación oficiosamente, la competencia de la CPI sobre el crimen de agresión estará supeditada al cumplimiento de las condiciones previstas en las normas arriba citadas. Adicionalmente, cabe resaltar que ambas condiciones deben concurrir para que se active la competencia de la CPI sobre el crimen de agresión; así lo establecen los entendimientos adoptados en el anexo III de la resolución objeto de la resolución adoptada en Kampala.

Cuestión que genera controversia es la relacionada con el procedimiento bajo el cual debe adoptarse la decisión de la mayoría de los Estados Parte prevista en el numeral 3. ${ }^{\circ}$ común a los artículos 15 bis y 15 ter. En particular, se trata de determinar si dicha decisión debe ser adoptada conforme al trámite previsto en el artículo 121 (4) del Estatuto o si, por el contrario, debe emplearse el procedimiento establecido en el artículo $121(5)^{109}$. No se trata de un debate de poca monta, pues conforme a la primera alternativa las enmiendas relacionadas con el crimen de agresión entrarían en vigor para todos los Estados Parte una vez las aprueben y ratifiquen siete octavos (7/8) de estos, en tanto que conforme la segunda opción tales enmiendas solo cobrarían vigencia para aquellos Estados Parte que las hayan ratificado ${ }^{110}$.

108 En todo caso, la jurisdicción de la Corte solo podrá ejercerse un año después de la última de las ratificaciones exigidas. Ver arts. 15 bis (2) y 15 ter (2)

109 En nuestro concepto el procedimiento de la adopción de la enmienda es el mismo, esto es, la aprobación por la Asamblea General de los Estados Parte por una mayoría de dos tercios de estos, de modo que lo que cambian son las condiciones de entrada en vigor.

110 En opinión de MiLANOviC será en últimas la CPI la que deberá definir si las enmiendas entrarán en vigor a través del artículo 121 (4) o 121 (5), teniendo en cuenta la opinión que los Estados acojan al respecto. El mencionado autor, además, señala una contradicción entre los artículos 15 bis (4) y 121 (5), ya que, mientras el primero dice que la Corte no ejercerá competencia cuando el crimen sea cometido tanto por nacionales como en el territorio de un Estado que no haya aceptado la enmienda (ya sea el Estado agresor o el Estado víctima), el segundo parece admitir la competencia de la Corte aun 
La resolución adoptada en Kampala brinda pocas luces al respecto. En efecto, adviértase que el numeral 1..$^{\circ}$ de la resolución expresamente establece que las enmiendas al Estatuto "entrarán en vigor de conformidad con lo dispuesto en el párrafo 5 del artículo 121 del Estatuto", lo que supone que todos los Estados Parte ratifiquen la enmienda para que la misma tenga efecto en su territorio y en relación con sus nacionales; de lo contrario el señalado numeral dispone que "La Corte no ejercerá su competencia respecto de un crimen comprendido en la enmienda cuando haya sido cometido por nacionales o en el territorio de un Estado Parte que no haya aceptado la enmienda". Pese a la claridad de la disposición transcrita, los artículos 15 bis y 15 ter parecen haber consagrado un procedimientos sui generis de entrada en vigor del ejercicio de la competencia de la Corte frente al crimen de agresión, conforme al cual una vez se obtengan las 30 ratificaciones a las que hace referencia el numeral $2 .^{\circ}$ común y se adopte la decisión prevista en el numeral $3 .^{\circ}$ común, la Corte tendrá competencia para enjuiciar a los nacionales de todos los Estados Parte por el crimen de agresión, independientemente de que hayan o no ratificado la enmienda. Como puede observarse, nos hallamos ante una auténtica antinomia que no puede ser superada mediante los criterios previstos en la Convención de Viena del Derecho de los Tratados.

Esta problemática ha sido advertida por buena parte de la doctrina consultada ${ }^{111}$, sin embargo, cabría destacar la posición de ZIMMERMANN, quien señala que el mecanismo de entrada en vigor de la enmienda previsto en los artículos 15 bis y 15 ter constituye una ruptura de los principios que guían la reforma de los tratados multilaterales y desquicia el sistema de reforma del Estatuto consagrado en el artículo $121^{[112]}$. Para el citado autor, la enmienda adopta un mecanismo de entrada en vigor sui generis, conforme al cual todos los Estados Parte, hayan ratificado o no la enmienda, quedarán sujetos a la competencia de la Corte sobre el crimen de agresión. A modo de "compensación” por la vinculatoriedad general de la enmienda, el numeral 14 del artículo 15 bis prevé la posibilidad, hasta ahora extraña al Estatuto, de que los Estados Parte presenten una declaración de no aceptación de la competencia de la Corte sobre el crimen de agresión ${ }^{113}$, de modo que en tal

cuando el Estado víctima haya declarado que no acepta esa competencia. Al respecto ver MiLANOVIC.

"Agresssion and legality", cit., pp. 177 ss.

111 Corredor Carvajal, ob. cit., p. 56; Trahan, ob. cit., p. 64; Kreß y HoltzendorfF, ob. cit., pp. 1208 y 1209; АмBos. El crimen de agresión después de Kampala, cit., p. 61.

112 Andreas Zimmermann. "Amending the amendment provisions of the Rome Statute: The Kampala Compromise on the Crime of Aggression and the Law of Treaties". Journal of International Criminal Justice, vol. 10(1), Oxford University Press, 2012, p. 221. Traducción libre.

113 En cuanto a la naturaleza de esta declaración de no aceptación de la competencia de la Corte, coincidimos con CORREDOR en cuanto a que se trata de una auténtica reserva que, en principio, estaría prohibida por el artículo 120 del ECPI. En opinión del autor: "La cuestión más compleja es aquella relacionada con la naturaleza jurídica de la declaración de no aceptación de la competencia de la Corte respecto del crimen de agresión, más allá de la claridad del artículo 120 del Estatuto, que no deja duda alguna y según el cual no se admitirán reservas al Estatuto. Sin embargo, al tenor del numeral 4, parece 
caso sus nacionales no podrán ser enjuiciados por este crimen internacional ${ }^{114}$. En palabras del citado autor:

Los artículos 15 bis y 15 ter representan una compleja mixtura de las normas que rigen la enmienda del Estatuto de la CPI previstas en los párrafos 3. ${ }^{\circ}, 4{ }^{\circ}$ y $5 .^{\circ}$ del artículo 121 del Estatuto: De modo similar al art. 121 (3), los arts. 15 bis (3) y 15 ter (3) prevén una nueva adopción de la enmienda sobre el crimen de agresión transcurrido un período de reflexión de siete (7) años. En concordancia con el principio subyacente al art. 121(4) la enmienda, como cuestión de principio, debe entrar en vigor para todos los Estados parte, sin embargo, tal entrada en vigor estará supeditada a la ratificación por 30 Estados en lugar de los 7/8 de todos los Estados parte, tal como lo exige el art. 121(4). Finalmente, el art. 15 bis (4) se asemeja al art. 121 (5) al excluir la jurisdicción de la Corte - frente al crimen de agresión- en relación con los Estados parte que no ratifiquen la enmienda, sin embargo simultáneamente obliga a dichos Estados -los que no ratifiquen la enmienda- a presentar una reserva [formally opt-out], en vez de operar la limitación automática a la jurisdicción de la Corte prevista en el art. $121(5)^{115}$.

A no dudarlo, la situación más compleja a las que se enfrentará la Corte una vez entre en vigor la enmienda se dará frente a los nacionales de Estados Parte que no han ratificado la enmienda y tampoco han presentado la declaración de reserva prevista en el artículo 15 bis (4); de seguro tales Estados alegarán que sus nacionales están excluidos de la jurisdicción de la Corte respecto del crimen de agresión en razón a lo expresamente previsto en el artículo 121 (5). En últimas será la Corte la que, por vía de autoridad, resuelva esta controversia.

\section{EL PRINCIPIO DE COMPLEMENTARIEDAD Y EL CRIMEN DE AGRESIÓN}

El artículo 1. ${ }^{\circ}$ del ECPI instituye una Corte Penal Internacional la cual "tendrá un carácter complementario de las jurisdicciones penales nacionales". Este enunciado pone de presente el principio medular del ejercicio de la jurisdicción por parte de

hacer sido manifiestamente desconocida. Aunque dicha disposición se presenta como 'salvo que ese Estado Parte haya declarado previamente que no acepta esa competencia mediante depósito de una declaración en poder del Secretario', tal declaración constituye indiscutiblemente una reserva del tratado, puesto que tiene por objetivo y efecto la modulación de los términos del compromiso internacional del Estado": CORREDOR CARVAJAL, ob. cit., p. 163.

114 Salvo que la situación sea remitida por el Consejo de Seguridad conforme lo parámetros previstos en el artículo 15 ter.

115 ZimmermanN. "Amending the amendment provisions of the Rome Statute: The Kampala Compromise on the Crime of Aggression and the Law of Treaties", cit., p. 221. 
la CPI, a saber: la CPI no ha sido creada para suplantar a los tribunales nacionales en la persecución de crímenes internacionales, sino para complementar dicha tarea ${ }^{116}$.

No es este el escenario para explicar en detalle el contenido y alcance del principio de complementariedad. En particular, nos limitaremos a indagar si el mentado principio tiene o no aplicación en tratándose del crimen internacional de agresión. Al respecto, sea lo primero señalar que en los distintos instrumentos internacionales que se han ocupado de esta conducta punible se ha arribado a conclusiones diametralmente opuestas. Así, por ejemplo, el proyecto de Código de Crímenes contra la Paz y la Seguridad de la Humanidad de 1996 proponía que la jurisdicción para conocer del crimen de agresión debía recaer exclusivamente en la $\mathrm{CPI}^{117}$. Por el contrario, el Estatuto de la CPI no establece limitación alguna al ejercicio de las jurisdicciones nacionales frente al crimen de agresión, es más, los entendimientos $\mathrm{n} .^{\circ} 4$ y n. ${ }^{\circ} 5$ a la enmienda adoptada en Kampala reconocen tácitamente la posibilidad de que las jurisdicciones nacionales avoquen conocimiento frente al crimen que nos ocupa ${ }^{118}$.

No obstante, debe reconocerse que el entendimiento n. 5 sí limita el alcance del principio de complementariedad respecto del crimen de agresión, al establecer que "las enmiendas no se interpretarán en el sentido de que crean el derecho o la obligación de ejercer la jurisdicción nacional respecto de un acto de agresión cometido por otro Estado". Recuérdese que la esencia del principio de complementariedad radica en que los Estados Parte están obligados a investigar aquellas infracciones graves a los derechos humanos recogidas bajo la forma de crímenes internacionales ${ }^{119}$, de modo

116 Beth van ShaAck. "Par in Parem Imperium Non Habet". Journal of International Criminal Justice, vol. 10, Oxford University Press, 2012, p. 134.

117 Así, el Informe de la Comisión de Derecho Internacional sobre la labor realizada en su $48 .^{\circ}$ período de sesiones (6 de mayo-26 de julio de 1996), destaca los siguientes argumentos: "Este principio de jurisdicción exclusiva es consecuencia del carácter singular del crimen de agresión, en el sentido de que la responsabilidad de una persona por su participación en este crimen queda establecida por su participación en una violación suficientemente grave de la prohibición de ciertas conductas de los Estados, contenida en el párrafo 4 del Artículo 2 de la Carta de las Naciones Unidas. La agresión atribuida a un Estado es condición sine qua non para establecer la responsabilidad de una persona por su participación en el crimen de agresión. Nadie puede incurrir en responsabilidad por este crimen si no hay agresión cometida por un Estado. Por consiguiente, el tribunal no puede zanjar la cuestión de la responsabilidad penal individual por este crimen sin considerar con carácter preliminar la cuestión de la agresión cometida por un Estado. La determinación, por el tribunal de un Estado, de la cuestión de si otro Estado ha cometido agresión sería contraria al principio fundamental del derecho internacional par in parem imperium non habet. Además, el hecho de que el tribunal de un Estado, en el ejercicio de su competencia, tuviera que considerar la comisión de un acto de agresión por otro Estado tendría consecuencias graves para las relaciones internacionales y la paz y la seguridad internacionales". El mencionado documento se puede consultar en http://legal.un.org/ilc/publications/yearbooks/ Ybkvolumes(s)/ILC_1996_v2_p2_s.pdf Consultado el 1 de septiembre de 2014.

118 SHAACK, ob. cit., p. 135.

119 A decir verdad se trata de una obligación de ius cogens que vincula a todos los Estados, no solo aquellos que han ratificado el Estatuto de la CPI. 
que la Corte solo debe intervenir cuando se quebrante dicho deber. Como puede advertirse, el anotado entendimiento, bajo una interpretación exegética, socava las bases del principio de complementariedad, al prever que la disposición que define el crimen de agresión no impone el correlativo deber de investigación y enjuiciamiento por parte de las jurisdicciones nacionales.

Lo anterior debe conducirnos a indagar por el valor de los mencionados entendimientos, más aún cuando -como aquí se interpreta- desquician el modelo bajo el cual la CPI está llamada a ejercer su jurisdicción. Para la doctrina consultada ${ }^{120}$ la interpretación más plausible de estos entendimientos es que se trata de medios de interpretación complementarios de acuerdo al artículo 32 de la Convención de Viena sobre el Derecho de los Tratados (CVDT) ${ }^{121}$, lo cual supone la discrecionalidad de la CPI en su aplicación; esto es, la Corte podrá optar por acudir o no a los mencionados entendimientos conforme advierta que las disposiciones recientemente incorporadas al Estatuto suponen retos hermenéuticos. Contrario sensu, cuando el tex to de la norma sea lo suficientemente claro a la luz de una interpretación literal o sistemática, no es imperativo adecuar su hermenéutica al texto de los entendimientos. Tal parece ser el caso del citado entendimiento, pues al no haberse modificado las disposiciones del Estatuto que consagran el principio de complementariedad, no hay razón para considerar que el mencionado principio o, lo que es lo mismo, el ejercicio de las jurisdicciones nacionales, no tenga aplicación frente al crimen de agresión.

No obstante, debe aceptarse, como lo destaca algún sector de la doctrina, que la judicialización del crimen de agresión por las autoridades nacionales comporta dificultades que, en principio, no son predicables del enjuiciamiento de los restantes crímenes internacionales consagrados en el Estatuto. En particular, el Estado contra el que se ejerce la fuerza armada siempre estará predispuesto a interpretar tal hecho como un acto de agresión. Por tal razón, VAN SHAACK sostiene que el ejercicio de la jurisdicción nacional frente al crimen de agresión debe limitarse únicamente a lo casos en que este concurra con crímenes de guerra o crímenes contra la humanidad; de modo que cuando el cargo principal se circunscriba al mero desarrollo de un acto de agresión, su enjuiciamiento debe confiarse a tribunales internacionales, en especial a la CPI $^{122}$. Adicionalmente, el citado autor destaca que el enjuiciamiento del crimen de agresión por las autoridades nacionales vulnera el principio "par in parem imperium

120 KeVIN JON Heller. "The Uncertain Legal Status of the Aggression Understandings". Journal of International Criminal Justice, vol. 10, Oxford University Press, 2012.

121 Convención de Viena sobre el Derecho de los Tratados, art. 32: "Medios de interpretación complementarios. Se podrá acudir a medios de interpretación complementarios, en particular a los trabajos preparatorios del tratado y a las circunstancias de su celebración, para confirmar el sentido resultante de la aplicación del artículo 31, o para determinar el sentido cuando la interpretación dada de conformidad con el artículo 31: a) deje ambiguo u oscuro el sentido; o b) conduzca a un resultado manifiestamente absurdo o irrazonable".

122 SHAACK, ob. cit., pp. 135 a 137. 
non habet" (un igual no tiene poder sobre otro igual), así como que en las jurisdicciones nacionales no operan filtros para el inicio de una investigación por este crimen, como sí existen en el ámbito internacional (el Consejo de Seguridad de las NU o la Sección de Cuestiones Preliminares de la CPI). En el plano práctico, el autor resalta que la escasa cooperación internacional y aspectos como la inmunidad diplomática pueden impedir que la investigación y el juzgamiento se lleven a cabo con éxito ${ }^{123}$.

En conclusión, el principio de complementariedad tiene plena aplicación en tratándose del enjuiciamiento del crimen internacional de agresión, sin embargo, con miras a preservar el principio de juez imparcial convendría que su investigación y sanción se adelantara por tribunales internacionales; al menos cuando el cargo principal contra los acusados se reduzca al desarrollo de un acto de agresión.

\section{CONCLUSIONES}

Tras este breve estudio del crimen internacional de agresión considero válido formular las siguientes conclusiones:

i. La definición del crimen de agresión alcanzada en Kampala y la consagración de las condiciones para el ejercicio de la jurisdicción de la CPI frente al mismo constituye el más reciente, y tal vez más trascendental, paso hacia la absoluta proscripción del uso de la fuerza armada por parte de los Estados por fuera de los estrictos parámetros de la CNU. En poco más de un siglo, la humanidad ha pasado del reconocimiento del ius ad bellum como atributo de la soberanía de los Estados a la responsabilidad penal de los dirigentes del Estado que incurre en un acto de agresión.

ii. Con anterioridad a la definición de crimen de agresión incorporada al Estatuto de la CPI, el derecho internacional limitaba la responsabilidad penal por el crimen de agresión a la planeación, preparación o ejecución de una guerra de agresión; de modo que otras formas ilícitas del uso de la fuerza armada quedaban por fuera del ámbito de punibilidad de este crimen internacional. Hoy todo acto de agresión que reúna las condiciones previstas en el artículo 8 bis puede dar lugar a la declaratoria de responsabilidad penal.

iii. El crimen de agresión responde a una estructura distinta a las de los restantes crímenes internacionales, pues la conducta individual objeto de enjuiciamiento no adhiere a un escenario generalizado de violencia, sino que lo antecede. 
iv. El listado de actos de agresión previsto en el parágrafo $2 .^{\circ}$ del artículo 8 bis es meramente enunciativo y no limita el universo de casos que pueden configurar un acto de agresión para los efectos del crimen internacional de agresión.

v. El común denominador de los supuestos consagrados como actos de agresión está representado en el hecho de que todos tienen la potencialidad de provocar una respuesta armada, en principio lícita, por parte del Estado agredido, lo que, a su vez, puede dar lugar al desarrollo de un conflicto bélico y, por esa vía, amenazar los valores de la paz, seguridad y bienestar de la comunidad internacional.

vi. El reconocimiento del crimen de agresión como crimen de dirigentes no impide que se estructuren las distintas formas de autoría y participación previstas en el artículo 25 frente a este crimen; pero en todo caso el autor o partícipe deberá reunir las condiciones previstas en el citado artículo 8 bis.

vii. Los usos ilícitos de la fuerza armada por parte de un Estado que no reúnan las condiciones previstas en el artículo 8 bis, no son substancial steps de un acto de agresión, sino ilícitos internacionales que, precisamente por no constituir un acto de agresión, carecen de entidad para comprometer la responsabilidad penal internacional de sus autores; cuando menos por el crimen internacional de agresión.

viii.El umbral de gravedad previsto en el artículo 8 bis no fue establecido para categorizar los actos de agresión -entre aquellos que constituyen una violación manifiesta a la CNU y aquellos que no-, sino para subsanar la ambigüedad de la norma primaria de prohibición del uso de la fuerza.

ix. Contrariamente a la opinión de la mayor parte de la doctrina consultada, consideramos que hay suficientes razones para concluir que la declaratoria de inexistencia de un acto de agresión por parte del Consejo de Seguridad impide que la CPI adelante el enjuiciamiento de este crimen.

x. La enmienda adoptada en Kampala consagró un procedimiento sui generis para su entrada en vigor, que desconoce el tenor literal del Estatuto.

xi. Nada se opone a que, en desarrollo del principio de complementariedad, los tribunales nacionales ejerzan su jurisdicción frente al crimen internacional de agresión, sin embargo, dicha posibilidad comporta dificultades que harían aconsejable que el enjuiciamiento de estos hechos correspondiera a la CPI.

xii. El Estado colombiano está en mora de adelantar un debate serio acerca de la posición que debe asumir frente a las reformas al Estatuto de la CPI adoptadas en Kampala, en particular, urge que se decida si se ratificará o no la enmienda y, de no ser así, si se presentarán reservas frente a la jurisdicción de la Corte para enjuiciar a los dirigentes colombianos por este crimen. 


\section{BIBLIOGRAFÍA}

Ambos, K. “¿Castigo sin soberano? La cuestión del ius puniendi en Derecho Penal Internacional, Una primera contribución para una teoría del derecho penal internacional consistente". Persona y Derecho, vol. 68, n. ${ }^{\circ}$ 1, 2013.

Ambos, K. "El marco jurídico de la justicia de transición", en AA.Vv. Justicia de transición. Con informes de América Latina, Alemania, Italia y España. K. AмBos y E. MaLARINo (EDS.). Bogotá, Temis, 2010.

Ambos, K. El crimen de agresión después de Kampala. L. TASSARA (TRAD.). Madrid, Dykinson, 2011.

Ambos, K. La Parte General del Derecho Penal Internacional. Bases para una elaboración dogmática. E. MALARINO (TRAD.). Uruguay, Konrad-Adenauer-Stiftung, 2005.

Aмвоs, K. Responsabilidad penal internacional en el ciberespacio. Bogotá, Universidad Externado de Colombia, 2014.

BASSIOUNI, M. Сн. Crimes against Humanity: Historical evolution and contemporary application. Cambridge, Cambridge University Press, 2011.

BOISTER, N. "The application of collective and comprehensive criminal responsibility for agression at the Tokyo International Military Tribunal". Journal of International Criminal Justice, vol. 8, 2010.

BRAUN, L. VON Y A. MicUS. “Judicial independence at risk". Journal of International Criminal Justice, vol. 10, Oxford University Press, 2012.

CASSESE, A. Cassese's International Criminal Law, 3. a ed. Oxford, Oxford University Press, 2013.

Corredor Carvajal, I. F. El crimen de agresión en Derecho Penal Internacional. Responsabilidad del individuo por actos de Estado. Bogotá, Universidad del Rosario, 2012.

CREEGAN, E. "Justified uses of force and the crime of aggression". Journal of International Criminal Justice, vol. 10, Oxford University Press, 2012.

DíAz Soto. La responsabilidad del dirigente de organizaciones criminales estructuradas jerárquicamente. Tesis de maestría, 2011.

HaEnen, I. "Classifying acts as crimes against humanity in the Rome Statute of the International Criminal Court". German Law Journal, vol. 14, n. ${ }^{\circ}$ 7, 2013. 
HeLler, K. J. "The uncertain legal status of the aggression understandings". Journal of International Criminal Justice, vol. 10, Oxford University Press, 2012.

JesCHeCK, H-H. "The General Principles of International Criminal Law Set out in Nuremberg, as mirrored in the ICC Statute". Journal of International Criminal Justice, vol. 2 (1), Oxford University Press, 2004.

Kreß, C. y L. von HoltzendorfF. "The Kampala Compromise on the Crime of Aggression”. Journal of International Criminal Justice, vol. 8, 2010.

LubAn, D. J. "Fairness to rightness: Jurisdiction, legality, and the legitimacy of International Criminal Law". Georgetown University Law Center, julio de 2008.

Milanovic, M. “Aggression and legality”. Journal of International Criminal Justice, vol. 10, Oxford University Press, 2012.

O'Connell, M. E. y M. Niyazmatov. "What is agression? Comparing the Jus ad Bellum and the ICC Statute". Journal of International Criminal Justice, vol. 10, Oxford University Press, 2012.

Owen, J. Nuremberg, el mayor juicio de la historia. E. Belmonte y F. Esteve (trad.). Barcelona, Crítica, 2007.

PAulus, A. "Second thoughts on the crime of aggression". The European Journal of International Law, vol. 20, n. ${ }^{\circ}$ 4, 2010.

Perdomo Torres, J. F. Justicia penal internacional. Reflexiones acerca del delito político, extradición y amnistía. Lima, Grijley, 2006.

Politi, M. "The ICC and the crime of aggression. A dream that came though and the reality ahead". Journal of International Law, vol. 10, 2012.

Rueda FERnÁndez, C. Delitos de Derecho Internacional, tipificación y represión internacional. Barcelona, Bosch, 2002.

SÁnchez SÁnchez, R. E. "La definición del crimen de agresión”. Derecho Penal Contemporáneo n. ${ }^{\circ}$ 39, 2012.

SHAACK, B. VAN. "Par in Parem Imperium Non Habet". Journal of International Criminal Justice, vol. 10, Oxford University Press, 2012.

SungA, L. S. "La jurisdicción 'ratione materiae' de la Corte Penal Internacional (arts. 5. ${ }^{\circ}$ a $10 .^{\circ}$ del Estatuto de Roma)". En: AA.vv. El Estatuto de Roma de la Corte 
Penal Internacional. K. Ambos y O. J. Guerrero (comps.). Bogotá, Universidad Externado de Colombia. 1999.

Trahan, J. “The Rome Statute's Amendment on the Crime of Aggression: Negotiations at the Kampala Review Conference". International Criminal Law Review, vol. 11, 2011.

Werle, G. Tratado de Derecho Penal Internacional. C. Cárdenas Aravena, J. Couso Salas, M. GutiérRez RodríGuez (TRADS.). Valencia, Tirant lo Blanch, 2011.

WILLS, A. G. "The crime of aggression and the resort to force against entities in statu nascendi”. Journal of International Criminal Justice, vol. 10, 2012.

Zimmermann, A. "Amending the Amendment Provisions of the Rome Statute: The Kampala Compromise on the Crime of Aggression and the Law of Treaties". Journal of International Criminal Justice, vol. 10(1), Oxford University Press, 2012. 